\title{
The impact of TFP growth on the unemployment rate: does on-the-job training matter?
}

\author{
Eva Moreno-Galbis * \\ GRANEM, GAINS-TEPP, IRES \& Cepremap \\ eva.morenogalbis@univ-angers.fr
}

\begin{abstract}
This paper seeks to gain insights into the relationship between growth and unemployment in a setting with heterogeneous skills, human capital accumulation, on-the-job training and capital-skill complementarity. We use an endogenous job destruction framework in the style of Mortensen and Pissarides (1998) with directed search. We show that, when growth accelerates, a larger share of unskilled workers seeks training, increasing firms' incentives to update job-specific technology (rather than destroying it). By magnifying the impact of growth on employment, the introduction of human capital issues allows the model to more closely match the estimated sensitivity of unemployment with respect to growth. When calibrated, the model manages to reproduce the aggregate capitalization effect estimated using OECD data. We find that growth reduces unemployment for individuals receiving training, while it increases the unemployment rate of unskilled workers without training (creative destruction effect).
\end{abstract}

Keywords: Growth, unemployment, training, capital-skill complementarity, human capital depreciation, capitalization, creative destruction effect

JEL: J23, J24, O33

*Address: GRANEM, Université d'Angers, 13 Allée François Mitterrand, 49013 Angers, Cedex 01, France. I am grateful for financial support from CEPREMAP. I thank François Langot for the long discussions we had about this work. His comments, advice and support have been extremely helpful. I also thank all participants of the SaM Conference 2011, PET 2012 and seminar participants at the University of Rennes 1. Naturally, all remaining errors are mine. 
"L'impact de la croissance sur le taux de chômage : quelle est le rôle de la formation en emploi ?"

Ce papier essaye d'approfondir la compréhension de la relation entre la croissance et le chômage à l'aide d'un cadre théorique considérant des niveaux de qualification hétérogènes, l'accumulation de capital humain, la formation en emploi et la relation de complémentarité entre niveau de qualification et nouvelles technologies. Nous proposons un modèle de recherche dirigée avec destruction endogène des emplois a la Mortensen et Pissarides (1998). Nous montrons que, lorsque la croissance s'accélère, une proportion plus large de travailleurs non qualifiés décide de suivre une formation, ce qui incite les firmes à moderniser la technologie utilisée en ces postes de travail (plutôt que les détruire). En augmentant l'impact positif de la croissance sur l'emploi, l'introduction des différents aspects liés au capital humain permet au modèle de reproduire la semi-élasticité du chômage par rapport a la croissance estimée par Pissarides et Vallanti (2007). En effet, lorsque le modèle est calibré et simulé, il prédit un effet capitalisation dominant au niveau agrégé, ce qui se correspond aux estimations obtenues à partir des données de l'OCDE. Par ailleurs, nous trouvons que la croissance diminue le chômage des individus qui décident de se former alors qu'elle augmente le chômage des individus qui ne se forment pas. 


\section{Introduction}

At the Lisbon Summit at the beginning of the new millennium, the European Heads of Government resolved that by 2010 Europe would be "the most competitive and dynamic knowledgebased economy in the world". Development of high quality vocational training in Europe is a crucial part of this strategy, especially for the improvement and adaptation of existing skills to technological changes and for the promotion of employability. As remarked by Acemoglu and Pischke (1998) even low education workers can benefit from changes in the demand for skills induced by technological progress if they receive training. OCDE economic reports reveal that the share of workers being trained on the job is not insignificant. If we consider training during the lifetime of people over 18, Eurostat statistics reveal an average participation rate of $52 \%$ (UE-27) in 2009. This percentage reaches almost $78 \%$ in the case of Denmark, $66 \%$ in the Netherlands, $61 \%$ in Finland, $57 \%$ in Germany, $55 \%$ in France, $51.2 \%$ in Italy and $46 \%$ in Spain. In the case of France, national reports reveal that in 2006, the proportion of workers receiving on-the-job training in organizations where technological change has been introduced in the past 12 months reached $62 \%$.

While on-the-job training seems to have played a crucial role in the economic development of western economies in recent years, it is absent from current literature on the relationship between unemployment and growth. As shown in the present paper, this represents a major limit for capturing the truly relationship between growth and unemployment given the particular nature of recent technological progress. Bresnahan, Brynjolfsson, and Hitt (2002) conclude that the increased use of information and communication technologies (ICT), changes in organization practices and changes in products and services, taken together are the skill-biased technological progress that calls for a higher skilled labor $\mathrm{mix}^{1}$ and thus for an increased importance of training. Jobs are on average more and more complex. A worker is now less likely to perform a unique task throughout her career. Computerization is associated with a decline in the demand for routine manual and cognitive tasks and with an increase in the demand for non-routine abstract tasks requiring a wider human capital (see Goos and Maning (2007), Autor, Levy, and Murnane (2003), Autor, Levy, and Kearney (2006), Spitz-Oener (2006) or Maurin and Thesmar (2004)).

Lindbeck and Snower (2000) distinguish between intratask learning (which corresponds to learn-

\footnotetext{
${ }^{1}$ Other major contributions to the skill-biased technological progress literature are Berman, Bound, and Griliches (1994), Machin and Van Reenen (1998), Krusell et al. (2000) or Caroli and Van Reenen (2001)
} 
ing by doing in the traditional sense) and intertask learning (the skills acquired in a particular task allow to improve the worker's performance in other tasks). The nature of recent technological progress enhances intertask learning but slowdowns intratask learning since ICT require wide human capital rather than an expertise in a single task. New technologies need human capital to become fully productive and, similarly, human capital (acquired through training) cannot become fully productive without a modern technology (see Bresnahan, Brynjolfsson, and Hitt (2002) or Krusell et al. (2000)). This major complementary relationship has been traditionally ignored by the literature on the relation between unemployment and growth. By ignoring the skill-biased nature of technological change and thus the complementary relation between human capital and technology, the previous literature underestimates the potential productivity gains associated with technological progress (growth), and thus underestimates the impact on unemployment. This may explain why this literature runs into trouble when attempting to reproduce the estimated semi-elasticity of unemployment with respect to growth.

The major contribution of this paper is showing that, by introducing human capital issues in a vintage framework in the style of Mortensen and Pissarides (1998), we magnify the impact of growth on unemployment rates. First, distinguishing between skilled and unskilled workers (heterogeneous skill workers) enables us to highlight the fact that jobs occupied by highly qualified workers have benefitted from growth brought about by recent technological change. In a model with homogeneous skill workers, the skilled-biased nature of technological progress cannot be captured. Second, when growth accelerates, the opportunity cost of training investment for workers is lower, shifting the human capital distribution to the right. Due to the complementary relation between human capital and technological progress, firms' incentive to update job-specific technology rather than destroy the job is higher when the worker gets trained since expected productivity gains are also higher. By increasing the number of positions positively affected by technological change, training (together with the complementary relation between human capital and technical progress) magnifies the impact of growth on the unemployment rate.

There is a non negligible amount of literature analyzing the relationship between growth and unemployment. This relation is often considered ambiguous. Indeed, when growth accelerates, there are two contradictory effects: on the one hand, as Pissarides (1990) shows, an acceleration of growth has a positive effect on the employment rate, because growth "freely" increases expected profits and then provides incentives to create new jobs (capitalization effect); on the 
other hand, Aghion and Howitt (1994) argue that growth fosters a "creative destruction" process inducing greater job destruction and reduced job creation, yielding higher unemployment rates (creative destruction effect). Even if theoretically the relationship seems ambiguous, at the empirical level the capitalization effect clearly exceeds the creative destruction effect (see Blanchard and Wolfers (2000), Pissarides and Vallanti (2007) or Tripier (2007)), fostering a negative relationship between growth and unemployment.

Pissarides and Vallanti (2007) present a vintage model in the style of Mortensen and Pissarides (1998) with a representative agent and underline the difficulty of reproducing the estimated impact of the capitalization effect on employment. Working with an OCDE database from 1965 to 1995, they find that a one percentage point increase in the growth rate should decrease unemployment by 1.0 to 1.5 percentage points. However, in order to match this semi-elasticity when simulating their model numerically, Pissarides and Vallanti are forced to assume not only that all technological progress is disembodied, but also that firms discount the profits of a new job over an infinite horizon and that wages are independent of labor market conditions. While the rigid wage hypothesis can be easily justified (see Pissarides (2009)), the two other hypotheses are clearly unrealistic (recent technological change has been proven to be embodied and OCDE job destruction rates are not zero).

Also using a panel of OCDE countries, Langot and Moreno-Galbis (2008) estimate the impact of growth on the employment rate of both young and older workers. They find that the capitalization effect dominates the creative destruction effect in the case of younger workers, whereas in the case of older workers, the creative destruction effect is dominant. Nevertheless, using a standard calibration, they do not manage to reproduce the estimated elasticities.

Previous studies based on Mortensen and Pissarides (1998)'s work seem therefore to be missing an important aspect of the labor market that prevents them from correctly reproducing the estimated semi-elasticity of the unemployment rate in terms of growth. Specifically, one of the main drawbacks of the traditional Mortensen and Pissarides (1998) framework is that workers are not allowed to react when their positions become less profitable. They simply wait for the firm's detruction or renovation decision. A more realistic framework should allow them to search on the job or train themselves to improve their relative productivity and avoid job destruction. Michaud (2007) has already shown that the predictive capacity of the Mortensen and Pissarides (1998) model is considerably improved when introducing on-the-job search ${ }^{2}$. An alternative

\footnotetext{
${ }^{2}$ The main problem with this approach is the issue of wage bargaining. Indeed, Shimer (2005) shows that the
} 
approach proposed in our paper involves introducing human capital issues in the style of Ljunqvist and Sargent $(2008)^{3}$. The skill-biased nature of recent technological progress is neglected in Pissarides and Vallanti (2007) or Langot and Moreno-Galbis (2008) since they do not consider human capital issues. The potential productivity gains linked to technological progress are underestimated since they consider skill-homogeneous workers and the complementary relation between human capital acquired through training and technological change is ignored. This may justify the difficulties found by these papers when trying to reproduce the estimated semi-elasticity of unemployment with respect to growth.

The interplay between growth and learning has already been analyzed in the literature. Chari and Hopenhayn (1991) study the lag between the appearance of a technology and its peak usage in an OLG model with ongoing technological change and investment in technology-specific human capital. The interactions between learning by doing, technological choices and the timing of adoption of new technologies are analyzed in a model without labor market frictions and partial transferability of the expertise accumulated by working in Parente (1994) and Jovanovic and Nyarko (1996). Laing, Palivos, and Wang (1995) develop an endogenous growth model with such frictions where they analyze how educational choices interact with wage determination and affect the growth rate. Carre and Drouot (2004) consider a Mortensen and Pissarides (1998) framework where they introduce intratask learning. They analyze how the change in the nature of technological progress modifies on-the-job learning and, through general equilibrium effects, unemployment and wage dispersion. In Carre and Drouot (2004), the expertise is technology-specific and so it is lost in case of technological change (there is no complementary relation between skills and technological progress). When intratask returns are high the pace of technological updating falls (firms want to take advantage of the possibility of a worker to accumulate expertise on its current technology) whereas when returns are low firms prefer to increase their productivity by changing the technology. Therefore, human capital accumulation discourages technological adoption in this framework. This counterfactual result is explained by the non-transferability of skills/expertise among different vintages of technology and the absence of a complementary relation between technological progress and human capital.

We consider a one job-one firm vintage model in the style of Mortensen and Pissarides (1998). In the main body of the paper, the model is resolved using the hypotheses that firms direct their standard solution to the wage bargaining process is not robust to the introduction of on-the-job search.

${ }^{3}$ Low-productivity workers are allowed to train themselves and skilled unemployed workers may experience human capital depreciation. 
vacancies to a particular human capital level and pay workers a wage equal to their reservation wage. In the appendix we develop the model using undirected search with wage posting and directed/undirected search with wage bargaining ${ }^{4}$. We have made a distinction between the machines' vintage and the workers' human capital level. Firms decide the optimal destruction or renovation horizon associated with a machine/position. When the optimal destruction horizon is below (above) the optimal renovation horizon, it is in the firm's interest to destroy (renovate) the job. Workers may be skilled (high-productivity) or unskilled (low productivity). Unskilled workers must decide whether it is in their best interest to train on the job. Those that get trained will be able to exploit the acquired human capital in the case of technological updating, so that the firm's productivity is improved twice: a higher level of human capital is combined with a more modern machine (complementary relation between new technologies and human capital). Since skilled workers are already assumed to have the highest human capital level, we have not considered the possibility of training for these workers. When losing their jobs, skilled workers have some probability of experiencing a depreciation of their human capital.

By introducing heterogeneous skill workers, the possibility of training for unskilled workers, the complementary relation between human capital and technological change and the risk of human capital depreciation during a period of unemployment, our theoretical framework increases the likelihood of a dominant capitalization effect at the aggregate level. The positive effect of growth on employment is obtained by three combined effects. Firstly, recent technological progress is skill-biased, so productivity in jobs occupied by skilled workers is always improved by technological progress (the capitalization effect always dominates). Secondly, since unskilled workers receiving training and skilled workers have a reservation wage below the outside option of employment $^{5}$, the firm's profits are higher than those achieved for unskilled workers not getting trained and the optimal destruction horizon is delayed. The probability of updating rather than destroying the job's technology increases. Finally, the complementary relation between human capital and technological progress is modeled by allowing skills acquired through on-the-job

\footnotetext{
${ }^{4}$ Even if the wage bargaining specification is our preferred one, we keep the wage posting hypothesis in the core of the paper for technical simplicity.

${ }^{5}$ As noted by Becker (1964) for a competitive market, workers can undertake an investment in skills quite easily by accepting a lower wage than their productivity during the period of training. In our frictional framework, for unskilled workers getting trained, having a job implies becoming skilled in case of technological updating. For skilled workers, losing a job means they may become unskilled in case of human capital depreciation. They are then prepared to accept a lower wage in order to find or to keep a job.
} 
training to become productive only if the firm updates the technology (better human capital requires a better technology to become productive, see Bresnahan, Brynjolfsson, and Hitt (2002)). An unskilled worker getting trained becomes skilled if the firm updates the job-associated technology. When growth accelerates, the share of workers getting trained increases (opportunity cost of training decreases), which implies that there is also an increase in the number of jobs for which it is in the firm's interest to update rather than destroy the technology. If jobs are updated, an unskilled worker getting trained becomes a skilled worker. The capitalization effect is always dominant in positions occupied by skilled workers (skill-biased technological progress). Our numerical simulations show that when using a standard calibration, an increase of one percentage point in the growth rate yields a reduction of more than one percentage point in the aggregate unemployment rate, which concurs with the estimates made by Pissarides and Vallanti (2007) using OECD data for the period 1965-1995. Indeed, while skilled and unskilled workers getting trained benefit from a reduction in unemployment rates (capitalization effect), unskilled workers not getting trained experience an increase in unemployment rates. One of the paper's most interesting results is that it shows the relative importance of the capitalization effect in terms of the creative destruction effect depends on workers' skills and training choices. Human capital issues thus determine the relationship between growth and unemployment.

The next section presents the model's main assumptions. Sections 3 and 4 describe the agents' behavior, the wage setting process and the labor flows. The equilibrium of the model is described in section 5, which also analyzes the relationship between renovation, training and growth. Section 6 presents the numerical simulations and section 7 concludes.

\section{The model's assumptions}

\subsection{Characterization of firms and workers}

We have built a matching model based on Mortensen and Pissarides (1998) where the economy is populated by a continuum of firms and workers. The characteristics of the technology are summarized by the creation time, $\tau$, and the current time, $t$. Firms decide whether or not to update the vintage of the technology.

The worker's characteristics are summarized by the vector $\{h, \sigma\}$, where $h=\{\bar{h}, \underline{h}\}$ corresponds to the human capital level (high or low) and $\sigma$ denotes training costs, which are inversely related to the worker's inherent ability. Specifically, a low (high) $\sigma$ reveals an individual's high 
(low) inherent ability that allows him/her to bear a lower (higher) training cost. Note that the individual cannot alter his own $\sigma$, which is considered to be an inherent characteristic but the human capital level $h$ is affected by training.

We will assume that the worker comes to the labor market with the human capital (high or low) corresponding to her previous educational choices (not analyzed in this paper). Given that skilled workers are already situated in the upper limit of skill values, they will not receive training ${ }^{6}$. Training is only applicable to unskilled workers. Once employed, the worker considers the possibility of receiving training so that she can acquire new skills that will become employable in the case of technological updating. The productivity of the job is then twice improved since there is a simultaneous increase in the human capital and in the technological vintage ${ }^{7}$.

Of course, the worker receives training if and only if she anticipates that the firm will renovate its technology, otherwise the skills acquired during the training period will not be productive. The old vintage technology does not allow the worker to employ these skills. We follow Lindbeck and Snower (2000) and assume that recent technological progress tends to eliminate returns to intratask learning. More precisely, we neglect the potential productivity gain associated with the continuous exposure to a task which, by its nature, is not transferable in case of technological change. While we agree that these returns may not be actually nil, they have only played a minor role in recent technological changes, as suggested by the counterfactual results of Carre and Drouot (2004) discussed in the introduction.

Since each individual possesses a different inherent ability, training costs may vary for each worker. Heterogeneity among workers is represented by distribution $G(\sigma)$, over the support $[\underline{\sigma}, \bar{\sigma}]$. We will determine a critical cost (ability) level $\widetilde{\sigma}$ below which unskilled workers decide to train themselves and above which unskilled workers do not get trained.

Skilled workers who lose their jobs may become unskilled with probability $\pi$ during their unemployment period. A skilled worker losing her human capital during an episode of unemployment becomes unskilled in the $\sigma$-segment corresponding to her ability. The hypothesis of human

\footnotetext{
${ }^{6}$ Introducing a skilled segment allows our framework to capture the skill-biased nature of recent technological change, which has improved the relative productivity of skilled workers and has thus stimulated the demand for this type of labor (see Berman, Bound, and Griliches (1994), Machin and Van Reenen (1998), Krusell et al. (2000) or Caroli and Van Reenen (2001)).

${ }^{7}$ This complementary relation between skills and recent technological progress, has been largely analyzed by the economic literature which concludes that combining high levels of technological progress with low levels of human capital or the opposite, leaves productivity unaffected or can even yield a decrease in the firms' productivity (see Krusell et al. (2000), Bresnahan, Brynjolfsson, and Hitt (2002) or Black and Lynch (2001)).
} 
capital deppreciation does not play a major role in determining our results (see the sensitivity analysis implemented in section 6). However, in the aim of realism, we introduce it as a part of the considered human capital issues.

Each firm employs only one worker. The productivity of unskilled workers depends on their human capital level and we denote it with $x(\underline{h})$. Because this human capital level is homogeneous across unskilled workers, productivity is also homogeneous. We do consider that in tasks implemented by unskilled workers, talent is not a major determinant of productivity. Conversely, the productivity of skilled workers depends not only on the human capital level of the worker but also on her talent, $x(\bar{h}, \sigma)$. In order to capture the skill-biased nature of recent technological changes, we assume that positions occupied by skilled workers are updated at the same pace as the technological frontier. In this context, we consider that the worker's talent (ability to learn new things and apply them to different technologies) is a determinant of productivity in these positions $^{8}$. This assumption is better justified in section 3.3 and its importance is evaluated in the numerical simulations presented in section 6 .

\subsection{The matching process}

The model is resolved using both undirected and directed search hypotheses. Analytical results remain similar regardless of the hypothesis being used so, in the aim of clarity, in the core of the paper we solve the model under the directed search hypothesis, undirected search being presented in appendix I. At each moment in time a mass $u(h, \sigma)$ for $h=\bar{h}, \underline{h}$ of unemployed workers and a mass $v(h)$ of vacant jobs coexist in the labor market.

Firms aim their vacancies at a particular human capital level, i.e., we will have to distinguish between $v(\bar{h})$ and $v(\underline{h})$. Qualified positions and skilled workers meet pairwise according to the matching function $M(u(\bar{h}), v(\bar{h}))$. The matching function corresponding to unqualified positions and unskilled workers is given by $M(u(\underline{h}), v(\underline{h}))$. Both are strictly increasing, concave, homogeneous of degree 1, satisfy Inada conditions and $M(0, v(h))=M(u(h), 0)=0$.

Labor market tightness for the skilled and unskilled segments are given respectively by $\theta(\bar{h})=$ $\frac{v(\bar{h})}{u(\bar{h})}$ and $\theta(\underline{h})=\frac{v(\underline{h})}{u(\underline{h})}$. This yields the following probabilities of filling a vacancy $q(\theta(h))=$

\footnotetext{
${ }^{8}$ The major role of these inherent abilities as a determinant of the worker's productivity in skilled positions was first invoked by Juhn and Pierce (1993), who point towards returns to unobserved skills as the a main factor behind the wage dispersion among skilled workers. In more recent papers Lemieux (2006) or Autor, Katz, and Kearney (2008) find also that within group inequality has grown substantially among high-educated workers while it has decreased (or changed little) for low-educated groups.
} 
$M(u(h), v(h)) / v(h)=M(1 / \theta(h), 1)$ and of finding a job $p(\theta(h))=M(u(h), v(h)) / u(h)=$ $M(1, \theta(h))$ for $h=\bar{h}, \underline{h}$.

\subsection{Technical progress and the firm's decision}

New jobs embody the most advanced technology available (the latest vintage). However, once created, productivity remains constant for the rest of the working life, $x(\underline{h})$ for unskilled workers and $x(\bar{h}, \sigma)$ for skilled workers. Job creation commits the firm to the technology available at that date. A firm without a worker advertises a job vacancy at a cost $p(t) c$ per period, where $p(t)=e^{g t}$ is a common growth factor and $g$ is the rate of productivity growth at the technological frontier (creation costs must increase at rate $g$ to ensure the existence of a steady state with balanced growth).

In newly created jobs, productivity grows at the exogenous rate $g=\dot{p}(t) / p(t)$ (new jobs always embody the most advanced technology available). Once the job is created at date $\tau$ its associated technology, $p(\tau) x(\underline{h})$ for unskilled workers and $p(\tau) x(\bar{h}, \sigma)$ for skilled, does not change unless the firm updates the technology used in the job. The opportunity cost of employment is represented by $p(t) b(h)$ for $h=\bar{h}, \underline{h}$, where $b(h)$ includes unemployment benefit, leisure, domestic production, etc. Because it increases in response to growth whereas the job's productivity remains constant, the surplus associated with a match is decreasing over time.

Once the job is created, two situations may arise: firstly, the firm can continue to produce using the technology embodied in the job at the creation date and wait until the technology becomes completely obsolete; secondly, the firm may decide to pay a fixed renovation cost, $I(h)$, to update the technology associated with a job and continue to produce with the same worker. When employing an unskilled worker getting trained, a technological update is also associated with a human capital increase from $\underline{h}$ to $\bar{h}$.

The firm chooses the optimal scrapping and renovation horizons associated with a given position. We denote as $R(\bar{h}, \sigma), R(\underline{h}, \sigma)$ and $R\left(\underline{h}^{n}, \sigma\right)$ the optimal renovation horizon for skilled workers, unskilled workers getting trained and unskilled workers not getting trained, respectively. Similarly, the scrapping horizons are denoted as $T(\bar{h}, \sigma), T(\underline{h}, \sigma)$ and $T\left(\underline{h}^{n}, \sigma\right)$, where $T(\underline{h}, \sigma)=T\left(\underline{h}^{n}, \sigma\right)$ since, in the absence of renovation, there is no incentive to train.

If the optimal scrapping horizon is above the optimal renovation horizon, the firm decides to update the technology rather than destroy it. Otherwise, if the scrapping horizon is below the renovation horizon, the firm destroys the job. To keep our representation as close as possible to 
Mortensen and Pissarides (1998) we will also assume that jobs may be destroyed by an exogenous shock with probability $\delta$.

\section{Workers}

\subsection{Employed workers}

Skilled workers do not train, since they are already endowed with the highest possible human capital level. The present discounted value of earnings in a job of vintage $\tau$ employing a skilled worker satisfies ${ }^{9}$ :

$$
\begin{aligned}
W(\tau, t, \bar{h}, \sigma) & =\int_{t}^{\tau+R(\bar{h}, \sigma)} e^{-(r+\delta)(s-t)}[w(\tau, s, \bar{h}, \sigma) \bar{h}+\delta U(s, \bar{h}, \sigma)] d s \\
& +e^{-(r+\delta)(\tau+R(\bar{h}, \sigma)-t)} W(\tau+R(\bar{h}, \sigma), \tau+R(\bar{h}, \sigma), \bar{h}, \sigma)
\end{aligned}
$$

where $w(\tau, t, \bar{h}, \sigma)$ stands for the wage per unit of human capital earned at date $t$ by a skilled worker operating a machine created at $\tau$. The term $\delta U(\tau, t, \bar{h}, \sigma)$ corresponds to the value obtained by the skilled worker in the case of job destruction (value of unemployment). The final term represents the discounted value of earnings in the job once technological updating has taken place and the new vintage equals $\tau+R(\bar{h}, \sigma)$.

Assuming $\tau=t=0$, the stationary time path for future labor market tightness allows us to conjecture that the values for an employed or unemployed skilled worker are proportional to productivity at the technology frontier, i.e. $W(t, t, \bar{h}, \sigma) \equiv p(t) W(\bar{h}, \sigma)$ and $U(t, \bar{h}, \sigma) \equiv$ $p(t) U(\bar{h}, \sigma)$, so that:

$$
W(\bar{h}, \sigma)=\int_{0}^{R(\bar{h}, \sigma)} e^{-(r+\delta-g) s}[w(\bar{h}, \sigma) \bar{h}+\delta U(\bar{h}, \sigma)] d s+e^{-(r+\delta-g) R(\bar{h}, \sigma)} W(\bar{h}, \sigma)
$$

The value of employment to an unskilled worker getting trained takes into account the fact that the worker will benefit from an increase in her human capital only if the firm renews its technology, i.e. after $R(\underline{h}, \sigma)$. It resolves the following asset pricing equation:

$$
\begin{aligned}
W(\underline{h}, \sigma) & =\int_{0}^{R(\underline{h}, \sigma)} e^{-(r+\delta-g) s}[w(\underline{h}, \sigma) \underline{h}-\sigma+\delta U(\underline{h}, \sigma)] d s+e^{-(r+\delta) R(\underline{h}, \sigma)} W(R(\underline{h}, \sigma), R(\underline{h}, \sigma), \bar{h}, \sigma) \\
& =\frac{w \underline{h}, \sigma) \underline{h}-\sigma+\delta U(\underline{h}, \sigma)}{r+\delta-g}+\frac{e^{-(r+\delta-g) R(\underline{h}, \sigma)}}{1-e^{-(r+\delta-g) R(\underline{h}, \sigma)}}[W(\bar{h}, \sigma)-W(\underline{h}, \sigma)]
\end{aligned}
$$

\footnotetext{
${ }^{9}$ Equation (1) is the solution to the differential equation $r W(\tau, t, \bar{h}, \sigma)=w(\tau, t, \bar{h}, \sigma) \bar{h}-\delta(W(\tau, t, \bar{h}, \sigma)-$ $U(t, \bar{h}, \sigma))+\dot{W}(\tau, t, \bar{h}, \sigma)$, where $w(\tau, t, \bar{h}, \sigma)$ stands for the wage per unit of human capital, $-\delta(W(\tau, t, \bar{h}, \sigma)-$ $U(t, \bar{h}, \sigma))$ stands for the expected loss in the case of job destruction (as shown later, using the hypothesis that firms own all the bargaining power, this term is irrelevant) and $\dot{W}(\tau, t, \bar{h}, \sigma)$ is the expected capital gain from changes in the value of employment during the process of adjustment to equilibrium.
} 
where $\tau=t=0$ and $W(t, t, \underline{h}, \sigma) \equiv p(t) W(\underline{h}, \sigma)$ and $U(t, \underline{h}, \sigma) \equiv p(t) U(\underline{h}, \sigma)$. Wages net of training costs are represented by $w(\underline{h}, \sigma) \underline{h}-\sigma$, the expected gain in case of job destruction is given by $\delta U(\underline{h}, \sigma)$ and the term $\left(\frac{e^{-(r+\delta-g) R(\underline{h}, \sigma)}}{1-e^{-(r+\delta-g) R(\underline{h}, \sigma)}}[W(\bar{h}, \sigma)-W(\underline{h}, \sigma)]\right)$ stands for the expected gain in the present discounted value of earnings once the firm has updated its technology and the worker has become skilled ${ }^{10}$.

The value of employment to an unskilled worker not receiving training resolves the following asset pricing equation:

$$
\begin{aligned}
W(\underline{h}, \sigma) & =\int_{0}^{R\left(\underline{h}^{n}, \sigma\right)} e^{-(r+\delta-g) s}[w(\underline{h}, \sigma) \underline{h}+\delta U(\underline{h}, \sigma)] d s+e^{-(r+\delta) R\left(\underline{h}^{n}, \sigma\right)} W\left(R\left(\underline{h}^{n}, \sigma\right), R\left(\underline{h}^{n}, \sigma\right), \underline{h}, \sigma\right) \\
& =\frac{w(\underline{h}, \sigma) \underline{h}+\delta U(\underline{h}, \sigma)}{r+\delta-g}
\end{aligned}
$$

where $\tau=t=0, w(\underline{h}, \sigma)$ represents the wage per unit of human capital and $\delta U(\underline{h}, \sigma)$ stands for the expected gain in the case of job destruction ${ }^{11}$.

\subsection{Unemployed workers}

An unemployed worker receives a flow of earnings $p(t) b \cdot h$ including unemployment benefits, leisure, domestic productivity, etc. This flow of earnings increases with the technology frontier and the human capital level.

The skilled job seeker comes into contact with a vacant slot at rate $p(\theta(\bar{h}))=\theta(\bar{h}) q(\theta(\bar{h}))$ and becomes unskilled with probability $\pi$. The value to a skilled worker of unemployment solves the following asset pricing equation:

$$
\begin{aligned}
r U(t, \bar{h}, \sigma)= & p(t) b \bar{h}+\theta(\bar{h}) q(\theta(\bar{h}))[W(t, t, \bar{h}, \sigma)-U(t, \bar{h}, \sigma)] \\
& -\pi[U(t, \bar{h}, \sigma)-U(t, \underline{h}, \sigma)]+\dot{U}(t, \bar{h}, \sigma)
\end{aligned}
$$

where, as already stated, $p(t) b \bar{h}$ stands for the flow of earnings obtained during the unemployment spell, $\theta(\bar{h}) q(\theta(\bar{h}))[W(t, t, \bar{h}, \sigma)-U(t, \bar{h}, \sigma)]$ represents the expected gain from finding a job and becoming employed, $\pi[U(t, \bar{h}, \sigma)-U(t, \underline{h}, \sigma)]$ corresponds to the expected loss in the case of human capital depreciation (since unemployment benefits are linked to the human capital level, becoming unskilled brings about a

\footnotetext{
${ }^{10}$ The present discounted value of earnings for an unskilled worker receiving training can then be rewritten as: $r W(\underline{h}, \sigma)=w(\underline{h}, \sigma) \underline{h}-\sigma+\delta(U(\underline{h}, \sigma)-W(\underline{h}, \sigma))+g W(\underline{h}, \sigma)+(r+\delta-g) \frac{e^{-(r+\delta-g) R(\underline{h}, \sigma)}}{1-e^{-(r+\delta-g) R(\underline{h}, \sigma)}}[W(\bar{h}, \sigma)-W(\underline{h}, \sigma)]$, where $W(\underline{\dot{h}}, \sigma)=g W(\underline{h}, \sigma)$ represents the expected capital gain from changes in the value of employment during the adjustment process.

${ }^{11}$ Rewriting equation (3) yields the following expression for the discounted present value of earnings: $r W(\underline{h}, \sigma)=$ $w(\underline{h}, \sigma) \underline{h}+\delta(U(\underline{h}, \sigma)-W(\underline{h}, \sigma))+W(\underline{h}, \sigma)$, where $W(\underline{h}, \sigma)=g W(\underline{h}, \sigma)$ is the expected capital gain from changes in the value of employment during the adjustment process.
} 
reduction in earnings) and $\dot{U}(t, \bar{h}, \sigma)$ is the expected capital gain from changes in the valuation of unemployment.

Unskilled job seekers come into contact with a vacancy at rate $p(\theta(\underline{h}))=\theta(\underline{h}) q(\theta(\underline{h}))$. The asset value of unemployment associated with unskilled workers is given by:

$$
\begin{aligned}
r U(t, \underline{h}, \sigma)= & p(t) b \underline{h}+\theta(\underline{h}) q(\theta(\underline{h}))[W(t, t, \underline{h}, \sigma)-U(t, \underline{h}, \sigma)] \\
& +\dot{U}(t, \underline{h}, \sigma)
\end{aligned}
$$

The interpretation of each term is the same as in the case of skilled workers.

\subsection{Wages}

In the interest of simplicity, the analysis presented in this paper considers that workers have zero bargaining power which implies that they are paid the reservation wage by firms ${ }^{12}$. The extreme zero bargaining power assumption enables an analysis of the relationship between renovation, training and growth developed in section 5.1 .

Under the hypothesis that firms possess all the bargaining power $W(\tau, t, h, \sigma)=U(t, h, \sigma)$ for $h=\bar{h}, \underline{h}$. Replacing $r W(\tau, t, \bar{h}, \sigma)=w(\tau, t, \bar{h}, \sigma)-\delta(W(\tau, t, \bar{h}, \sigma)-U(\tau, t, \bar{h}))+W(\tau, \dot{t}, \bar{h}, \sigma)$ and equation (4) with the previous equality leads to $w(\tau, t, \bar{h}, \sigma) \bar{h}=p(t) b \bar{h}-\pi(U(t, \bar{h}, \sigma)-U(t, \underline{h}, \sigma))$. From equations (4) and (5), we find that $U(t, \bar{h}, \sigma)-U(t, \underline{h}, \sigma)=p(t) \frac{b \bar{h}-b \underline{h}}{r+\pi-g}$, so that the wage paid by firms to skilled workers equals:

$$
w(\tau, t, \bar{h}, \sigma) \bar{h}=p(t)\left[b \bar{h}-\pi \frac{b \bar{h}-b \underline{h}}{r+\pi-g}\right] \quad \forall \sigma \quad \Rightarrow w(\tau, t, \bar{h}, \sigma) \bar{h}=w(\tau, t, \bar{h}) \bar{h}
$$

The wage earned in the skilled segment is the same for all workers, independently of the firm in which they work. A skilled worker is likely to accept a wage lower than her own unemployment benefit since she interiorizes the fact that if she becomes unemployed her human capital may depreciate and her unemployment benefit will then fall.

Unskilled workers getting trained become skilled when the firm updates its technology. Under the wage posting hypothesis, $W(\underline{h}, \sigma)=U(\underline{h}, \sigma)$. Replacing in equation (2) we find:

$$
U(\underline{h}, \sigma)=\frac{w(\underline{h}, \sigma)-\sigma+\delta U(\underline{h}, \sigma)}{r+\delta-g}+\frac{e^{-(r+\delta-g) R(\underline{h}, \sigma)}}{1-e^{-(r+\delta-g) R(\underline{h}, \sigma)}}[U(\bar{h}, \sigma)-U(\underline{h}, \sigma)]
$$

Subtracting (5) from (4) and replacing in (7), yields the reservation wage paid to unskilled workers getting trained:

$$
w(\tau, t, \underline{h}, \sigma)=p(t) b \underline{h}+p(t) \sigma-(r+\delta-g)\left(\frac{e^{-(r+\delta-g) R(\underline{h}, \sigma)}}{1-e^{-(r+\delta-g) R(\underline{h}, \sigma)}}\right) \frac{p(t) b(\bar{h}-\underline{h})}{r+\pi-g}
$$

The wage paid to an unskilled worker getting trained increases with his own unemployment benefit and the training cost. Less talented workers (higher $\sigma$ ) incur a higher training cost than more talented workers

\footnotetext{
${ }^{12}$ The resolution of the model where both workers and firms have positive bargaining power is shown in appendix J.
} 
(lower $\sigma$ ), so the minimum wage they are ready to accept to supply labor (their reservation wage) will be above the minimum wage required by more talented workers. Wages of unskilled workers getting trained vary with $\sigma$, implying that there is a continuum of wages and thus a continuum of instantaneous profits obtained by the firm. The profit is greater when the position is occupied by a worker with greater ability (low $\sigma$ ), since the reservation wage paid by the firm is lower. This delays the optimal scrapping or renewing decisions. If the expected productivity gains after renovation do not differ between high and low talented workers, jobs occupied by less talented unskilled workers will be updated before since the profit associated with these positions is lower (the firm must face the renovation decision earlier). By allowing productivity gains after technological updating to be larger for high talented workers $(x(\bar{h}, \sigma)$ decreases with $\sigma$ ) our framework avoids this counterintuitive result. In summary, the relative improvement in the expected productivity gains after renovation for high talented workers manages to compensate the wage effect, which tends to advance the renewing decision for less talented workers.

When the unskilled worker does not get trained, the reservation wage equals:

$$
w(\tau, t, \underline{h}, \sigma) \underline{h}=p(t) b \underline{h} \quad \forall \sigma \quad \Rightarrow w(\tau, t, \underline{h}, \sigma) \underline{h}=w(\tau, t, \underline{h}) \underline{h}
$$

For workers not receiving training, i.e: having a $\sigma>\widetilde{\sigma}$, the training cost does not affect wages and so the labor market is not segmented: productivity and wages are homogenous among these workers.

\subsection{The decision to train}

It is in the interest of an unskilled worker to get trained if the training cost is lower than or equal to the returns obtained from that training. Since it is assumed that on-the-job training will take place between the job creation date and the renovation date, the worker must pay a cost every period. Indeed it is as if the training cost were a lump-sum payment annualized throughout the training period defined between $[\tau, R(\underline{h}, \sigma)]$. In the case of wage posting $W(\tau, t, \bar{h}, \sigma)=U(t, \bar{h}, \sigma)$ and $W(\tau, t, \underline{h}, \sigma)=U(t, \underline{h}, \sigma)$, using equations (4) and (5) we find:

$$
\begin{aligned}
\tilde{\sigma} \int_{0}^{R(\underline{h}, \sigma)} e^{-(r+\delta-g) s} d s & =e^{-(r+\delta-g) R(\underline{h}, \sigma)}[W(\bar{h}, \sigma)-W(\underline{h}, \sigma)] \\
\tilde{\sigma} & =\frac{e^{-(r+\delta-g) R(\underline{h}, \tilde{\sigma})}}{1-e^{-(r+\delta-g) R(\underline{h}, \tilde{\sigma})}} \frac{r+\delta-g}{r+\pi-g} b(\bar{h}-\underline{h})
\end{aligned}
$$

As far as $\sigma \leq \tilde{\sigma}$, it is always in the worker's interest to get trained ${ }^{13}$. If we apply this training situation to equation (8), we can deduce that workers receiving training have a reservation wage below $b \underline{h}$ since for them access to a job is also associated with the opportunity to become skilled (and earn a higher wage) when technological updating takes place. This expectation of better quality jobs leads them to accept a lower recruiting wage.

\footnotetext{
${ }^{13}$ For simplicity, in the calibration exercise we have standardized the support of $\sigma$ to unity so that $[\underline{\sigma}, \bar{\sigma}]=[0,1]$. The parameter values adopted ensure that $\tilde{\sigma} \epsilon[0,1]$. However, extreme parameter values could yield corner solutions if $\tilde{\sigma}$ is below 0 or above 1 .
} 
If $\sigma>\tilde{\sigma}$, the worker never gets trained. If she did get trained she would ask for a wage above $b \underline{h}$ (see equation (8)), and no firm would hire her. Firms prefer to hire workers with greater ability who ask for a lower wage.

\section{Firms}

\subsection{Job occupied by a skilled worker}

Let us start with the expected flow of profits when the vacancy is filled by a skilled worker. The firm chooses the optimal moment to update so as to maximize the expected flow of profits, taking into account the fact that the job may be destroyed with probability $\delta$ :

$$
\begin{aligned}
J(\tau, t, \bar{h}, \sigma)= & \max _{R(\bar{h}, \sigma)} \int_{t}^{\tau+R(\bar{h}, \sigma)} e^{-(r+\delta)(s-t)}\left[p(\tau) x(\sigma) \bar{h}-w^{s}(\tau, s, \bar{h}, \sigma) \bar{h}\right] d s \\
& +e^{-(r+\delta)(\tau+R(\bar{h}, \sigma)-t)}[J(\tau+R(\bar{h}, \sigma), \tau+R(\bar{h}, \sigma), \bar{h})-p(\tau+R(\bar{h}, \sigma)) I(\bar{h})]
\end{aligned}
$$

where $I(\bar{h})$ stands for the exogenous renovation cost associated with qualified positions. The expected flow of profits includes the expected profits before renovation (integral term) plus the actualized net surplus of renovation. Because productivity of a skilled worker increases with her talent $\left(x^{\prime}(\sigma)<0\right)$, the optimal moment to update varies with $\sigma$.

Lemma 1 The optimal renovation date for a job occupied by a skilled worker depends on the worker's training cost $\sigma$ via the productivity $x(\sigma)$. The renovation horizon decreases with the growth rate of technical progress and increases with the updating and training costs.

Proof: See appendix B.

The optimal renovation horizon is thus given by:

$$
I(\bar{h})=x(\sigma) \bar{h} \int_{0}^{R(\bar{h}, \sigma)} e^{-(r+\delta) s}\left(1-e^{g(s-R(\bar{h}, \sigma))}\right) d s
$$

For a given $I(\bar{h})$, the higher $\sigma$ the lower $x(\sigma)$ and the higher $R(\bar{h}, \sigma)$. Similarly, for a given $x(\sigma)$, the higher the updating cost, the higher the renovation horizon, $R(\bar{h}, \sigma)$. Equation (13) determines $R(\bar{h}, \sigma)$, which can then be replaced in (12) when $\tau=t=0$ (equation (29) in appendix B) so as to find the optimal value of $J(\bar{h}, \sigma)$.

In order to reproduce the skill-biased nature of recent technological progress, we will assume that in the skilled segment renovation (rather than destruction) is always the preferred option. This is guaranteed if $I(\bar{h}) \rightarrow 0$. In this case, equation (13) implies that jobs are continuously updated since $R(\bar{h}, \sigma) \rightarrow 0$. In other words, if renovating a job is costless, it is in the interest of the firm to continuously renovate at the rate at which the technological frontier progresses. Thus, the value function of a job occupied by a skilled worker becomes $J(\bar{h}, \sigma)=\frac{x(\sigma) \bar{h}-w(\bar{h})}{r+\delta-g}$ where the impact of a growth acceleration, $g$, is unambiguously positive (capitalization effect). 


\subsection{Job occupied by an unskilled worker getting trained}

Similarly, a firm employing an unskilled worker getting trained chooses the optimal update time so as to maximize the expected profits before renovation (integral term) plus the actual net surplus of renovation, which confirms the fact that the unskilled worker becomes skilled after technological updating (complementary relation between human capital and technological change). Under the hypothesis that $\tau=t=0$ and the value of a new job is proportional to productivity on the technology frontier (given the stationary timeline for future labor market tightness), the firm's optimization problem is shown by:

$$
\begin{aligned}
J(\underline{h}, \sigma)= & \max _{R(\underline{h}, \sigma)}\left\{\int_{0}^{R(\underline{h}, \sigma)} e^{-(r+\delta) s}\left[x \underline{h}-e^{g s} w(\underline{h}, \sigma) \underline{h}\right)\right] d s \\
& \left.+e^{-(r+\delta-g) R(\underline{h}, \sigma)}[J(\bar{h}, \sigma)-I(\underline{h})]\right\}
\end{aligned}
$$

where $I(\underline{h})$ corresponds to the updating cost associated with an unskilled worker. In this case, the wage is a function of specific worker ability $(\sigma)$. We then have a $\sigma$-specific optimal update time.

Lemma 2 The optimal renovation horizon of a job occupied by an unskilled worker getting trained depends on training cost $\sigma$ via the wage and potential productivity achieved when the worker becomes skilled. The optimal renovation time increases with the updating cost, decreases with the technical progress growth rate and, for reasonable parameter values, increases with the training cost.

Proof: See appendix C.

The solution to the optimizing problem in (14) equals:

$$
I(\underline{h})=J(\bar{h}, \sigma<\tilde{\sigma})-J(\underline{h}, \sigma<\tilde{\sigma})+x \underline{h} \int_{0}^{R(\underline{h}, \sigma)} e^{-(r+\delta) s}\left(1-e^{g(s-R(\underline{h}, \sigma))}\right)
$$

For any $\sigma<\tilde{\sigma}$, the value of $J(\bar{h}, \sigma<\tilde{\sigma})$ can be obtained from the skilled's optimizing problem (section 4.1). The optimal, $R(\underline{h}, \sigma)$ can be found using equations (8) and (32) (in appendix C). Once $J(\bar{h}, \sigma<\tilde{\sigma})$ and $R(\underline{h}, \sigma)$ are determined, it is easy to find $J(\underline{h}, \sigma)$ from (15).

\subsection{Job occupied by an unskilled worker not getting trained}

If the job is filled by an unskilled worker not getting trained, the expected flow of profits maximized by the firm is given by:

$$
\begin{aligned}
J(\underline{h}, \sigma)= & \max _{R\left(\underline{h}^{n}, \sigma\right)} \int_{0}^{R\left(\underline{h}^{n}, \sigma\right)} e^{-(r+\delta) s}\left[x \underline{h}-e^{g s} b \underline{h}\right] d s \\
& +e^{-(r+\delta-g) R\left(\underline{h}^{n}, \sigma\right)}[J(\underline{h}, \sigma)-I(\underline{h})]
\end{aligned}
$$

for $J(t, t, \underline{h}, \sigma)=p(t) J(\underline{h}, \sigma)$ and $\tau=t=0$. The optimal updating time is homogenous among all unskilled workers not receiving training because neither their wages nor their productivity are $\sigma$-specific. 
Lemma 3 The optimal renovation date for a job occupied by an unskilled worker not getting trained does not depend on the training cost ${ }^{14}$. The optimal renovation horizon increases with the updating cost and decreases with the technical progress growth rate.

Proof: See appendix D.

The optimal renovation horizon is given by:

$$
I(\underline{h})=x \underline{h} \int_{0}^{R\left(\underline{h}^{n}, \sigma\right)} e^{-(r+\delta) s}\left(1-e^{g\left(s-R\left(\underline{h}^{n}, \sigma\right)\right)}\right)
$$

Once we obtain $R\left(\underline{h}^{n}, \sigma\right)$ for all $\sigma>\tilde{\sigma}$, we can replace it in (16) to obtain the optimal $J(\underline{h}, \sigma)$.

\subsection{Vacancies}

When a firm creates a vacancy at date $t$ it assumes a cost $p(t) c$. Directed search hypothesis implies that the labor market is divided between skilled workers who only apply for qualified positions and unskilled workers who can only apply for unskilled positions. We will assume that in the case of deviation (a skilled worker applying for an unqualified position or vice-versa), the productivity of the match is zero so it is no longer in the interest of the firm or the worker to pursue the match.

The value of an empty vacancy posted in the skilled segment is given by:

$$
r V(t, \bar{h})=-p(t) c+q(\theta(\bar{h}))(\overline{J(t, t, \bar{h}, \sigma)}-V(t, \bar{h}))+V(\dot{t}, \bar{h})
$$

while that associated with a vacancy posted in the unskilled segment equals:

$$
r V(t, \underline{h})=-p(t) c+q(\theta(\underline{h}))(\overline{J(t, t, \underline{h})}-V(t, \underline{h}))+V(\dot{t}, \underline{h})
$$

where $\overline{J(t, t, \bar{h}, \sigma)}=\int_{\underline{\sigma}}^{\tilde{\sigma}} \frac{u(\bar{h}, \sigma)}{u(\bar{h})} J(t, t, \bar{h}, \sigma)$ and $\overline{J(t, t, \underline{h})}=\int_{\underline{\sigma}}^{\tilde{\sigma}} \frac{u(\underline{h}, \sigma)}{u(\underline{h})} J(\underline{h}, \sigma<\tilde{\sigma}) d G(\sigma)+\int_{\tilde{\sigma}}^{\bar{\sigma}} \frac{u(\underline{h}, \sigma)}{u(\underline{h})} J(\underline{h}, \sigma>$ $\tilde{\sigma}) d G(\sigma)$ represents the expected value of a vacancy filled by an unskilled worker.

In the equilibrium, firms create vacancies until all rents are exhausted, i.e. : $V(t, \bar{h})=0, V(t, \underline{h})=0$. Market tightness at date $t$ in the skilled and unskilled market segments satisfies respectively:

$$
\frac{p(t) c}{q(\theta(\bar{h}))}=\overline{J(t, t, \bar{h}, \sigma)} \quad \text { and } \quad \frac{p(t) c}{q(\theta(\underline{h}))}=\overline{J(t, t, \underline{h})}
$$

Directed search hypothesis implies that there are two distinct labor market tightness. This means that we may encounter a situation where the capitalization effect (increase in labor market tightness) dominates in one segment while the creative destruction effect dominates in the other segment. The aggregate behavior of the unemployment rate will depend on the progression of each segment.

\subsection{Skilled and unskilled unemployment rates}

Let us start with unemployment rates for skilled and unskilled workers receiving training. If it is optimal for firms to renovate positions occupied by unskilled workers getting trained, the only source of job

\footnotetext{
${ }^{14}$ For notational homogeneity among workers we will retain the notation $R\left(\underline{h}^{n}, \sigma\right)$.
} 
destruction for these workers is the exogenous shock $\delta$. The equilibrium unemployment rate for any $\sigma<\tilde{\sigma}$ can then be found by equalizing the entries and exits from employment. We will normalize to one the total population associated with each ability level $\sigma<\tilde{\sigma}$. Using a simplified notation we note that, for every $\sigma<\tilde{\sigma}, P(\underline{h})+P(\bar{h})=1$, where $P(\underline{h})=u(\underline{h})+E(\underline{h})$ and $P(\bar{h})=u(\bar{h})+E(\bar{h})$.

Exists from employment will be given by $\delta E(\underline{h})+p(\theta(\underline{h})) u(\underline{h}) e^{-\delta R(\underline{h}, \sigma)} . E(\underline{h})$ and $u(\underline{h})$ represent the number of unskilled employed and unemployed workers getting trained and $p(\theta(\underline{h})) u(\underline{h}) e^{-\delta R(\underline{h}, \sigma)}$ the fraction of job creation that survives to exogenous destruction that is then renovated (becomes skilled). Entries to employment are given by $p(\theta(\underline{h})) u(\underline{h})$. The equilibrium flow equation is then equal to:

$$
p(\theta(\underline{h})) u(\underline{h})=\delta E(\underline{h})+p(\theta(\underline{h})) u(\underline{h}) e^{-\delta R(\underline{h}, \sigma)}
$$

Using the same reasoning we can establish the equilibrium flow equation for skilled workers:

$$
p(\theta(\bar{h})) u(\bar{h})+p(\theta(\underline{h})) u(\underline{h}) e^{-\delta R(\underline{h}, \sigma<\tilde{\sigma})}=\delta E(\bar{h})
$$

To keep the population of skilled and unskilled workers constant, external outflows and inflows from each population category must be equalized. Specifically, the number of skilled workers experiencing a depreciation of their human capital must equal the number of unskilled workers whose positions are renovated and thus whose human capital is improved:

$$
p(\theta(\underline{h})) u(\underline{h}) e^{-\delta R(\underline{h}, \sigma<\tilde{\sigma})}=\pi u(\bar{h})
$$

We note that, for an ability level $\sigma<\tilde{\sigma}$, there is a system of four equations and four unknowns: $u(\underline{h})$, $u(\bar{h}), P(\underline{h}), P(\bar{h})$. Combining equations $(22)$ and $(23)$ yields $(p(\theta(\bar{h}))+\pi+\delta) u(\bar{h})=\delta P(\bar{h})$. Similarly, from equation (21) we obtain: $\delta P(\underline{h})=u(\underline{h})\left(p(\theta(\underline{h}))\left(1-e^{-\delta R(\underline{h}, \sigma)}\right)+\delta\right)$. We then have the following unemployment rates:

$$
u(\underline{h}) / P(\underline{h})=u^{R}(\underline{h})=\frac{\delta}{p(\theta(\underline{h}))\left(1-e^{-\delta R(\underline{h}, \sigma)}\right)+\delta} \quad u(\bar{h}) / P(\bar{h})=u^{R}(\bar{h})=\frac{\delta}{p(\theta(\bar{h}))+\pi+\delta}
$$

When considering unskilled workers not getting trained, we apply the same reasoning by normalizing the population associated with each $\sigma>\tilde{\sigma}$ to one. As in the previous case, job creation flows must equal job destruction flows. In this instance, when the job is renovated, the individual does not change her type and remains unskilled. Equalizing entry $(p(\theta(\underline{h})) u(\underline{h}))$ and exit $(\delta(1-u(\underline{h})))$ flows from employment within a given $\sigma>\tilde{\sigma}$ leads to:

$$
u(\underline{h})=\frac{\delta}{\delta+p(\theta(\underline{h}))}
$$

When renovation is not optimal for the firm there are two sources of job destruction: exogenous shock and endogenous decision made by the firm ${ }^{15}$. In the absence of renovation there is no incentive for unskilled

\footnotetext{
${ }^{15}$ We have assumed in this paper that renovation costs in the skilled segment are equal to zero, therefore in the skilled segment renovation is always optimal and the capitalization effect dominates.
} 
workers to seek training. Entries to unemployment are a result of exogenous job destruction, $\delta(P(\underline{h})-$ $u(\underline{h}))$ and from the fraction of job creation that survives to exogenous destruction, $p(\theta(\underline{h})) u(\underline{h}) e^{-(\delta) T^{*} \underline{h}}$ and that is endogenously destroyed. Exits from unemployment correspond to the rate at which workers are matched with jobs $p(\theta(\underline{h})) u(\underline{h})$. Equalizing entries and exits yields the following unemployment rate:

$$
\frac{u(\underline{h})}{P(\underline{h})}=\frac{\delta}{\delta+p(\theta(\underline{h}))\left(1-e^{-\delta T^{\underline{h}}}\right)}
$$

\section{Equilibrium}

An equilibrium solution to the model consists of a threshold ability level separating unskilled workers getting trained and unskilled workers not getting trained, a set of optimal renovation horizons, a set of optimal scrapping horizons and two kinds of market tightness (skilled and unskilled).

- The division of the pool of unskilled workers into those that get trained and those that do not is given by equation (11).

- Since we assume that renovating the technology used by skilled workers is costless, firms continuously update these positions, implying that the optimal renovation horizon converges to zero. Equations (8) and the FOC associated with the optimizing problem in (14) (equation (32) in appendix C) allow us to calculate the optimal renovation horizon for unskilled workers receiving training, whereas equation (17) gives the optimal renovation horizon for unskilled workers not getting trained.

- Combining the job creation rules (equation (20)) with the employment flow equations defined in section 4.5, allows us to obtain labor market tightness as well as unemployment rates.

- Equations (27) and (28) in appendix A yield the optimal scrapping horizon for skilled and unskilled workers, respectively. Calculating these horizons is necessary in order to determine when it is in the interest of the firm to renovate (firms compare the optimal scrapping horizon and the optimal renovation horizon of a job).

Once these equilibrium values are determined, we can easily calculate wages, the value of a filled vacancy and the value for employment or unemployment.

\subsection{Interaction between renovation, training decisions and growth}

We study first the relationship between growth and employment for various types of workers. Secondly, we will analyze the relationship between training and renovation decisions. Finally, we will study the impact of growth on the proportion of workers being trained on the job. We did not employ job creation rules or equilibrium flow equations in any of the three points analyzed in the following subsections, implying that the results stand regardless of whether we use directed or undirected search hypothesis. 


\subsubsection{The capitalization vs. the creative-destruction effect}

It is in the interest of the firm to renovate if and only if the renovation cost is lower than the search cost. In this case, the optimal update time $R(h, \sigma)$ is below the optimal scrapping time $T^{(h, \sigma)}$ for $h=\bar{h}, \underline{h}$ (see the appendix A for the derivation of $\left.T^{(h, \sigma)}\right)$ :

$$
\begin{aligned}
& I(\bar{h}) \leq J^{*}(\bar{h}, \sigma) \quad \Leftrightarrow R(\bar{h}, \sigma)<T^{(\bar{h}, \sigma) \quad \text { for a skilled worker }} \\
& I(\underline{h}) \leq J^{*}(\underline{h}, \sigma) \quad \Leftrightarrow \quad R(\underline{h}, \sigma)<T^{\underline{h}} \quad \text { for an unskilled worker getting trained } \\
& I(\underline{h}) \leq J^{*}(\underline{h}, \sigma) \Leftrightarrow R\left(\underline{h}^{n}, \sigma\right)<T^{\underline{h}} \quad \text { for an unskilled worker not getting trained }
\end{aligned}
$$

Updating job-specific technology is a necessary but not sufficient condition for the capitalization effect to dominate the creative destruction effect. Even if it is in the interest of the firm to update a job rather than destroy it, this does not mean that the expected net profits will increase when growth accelerates. In the case of technological renovation, we must distinguish the two opposite effects: on the one hand, there is a labor cost effect due to the fact that wages increase at the same pace as the technological frontier; on the other, there is an actualization effect due to the increase in productivity through technological updating. If the labor cost effect is greater than the actualization effect the firm's profit net of renovation costs decreases with growth, yielding a reduction in the number of vacancies. Conversely, if the actualization effect is greater than the labor cost effect, net profit is improved with growth and there is a dominant capitalization effect.

We capture the skill-biased nature of technological progress by assuming that $I(\bar{h}) \rightarrow 0$, which implies that $R(\bar{h}, \sigma) \rightarrow 0$. Renovation is then the preferred option in the skilled segment $\left(R(\bar{h}, \sigma)<T^{(\bar{h}, \sigma)}\right)$ and the capitalization effect is always dominant when growth accelerates $\left(\frac{\partial J(\bar{h}, \sigma)}{\partial g}=\frac{(x(\sigma)-b) \bar{h}}{(r+\delta-g)^{2}}>0\right)$.

For the pool of unskilled workers, the following proposition holds true:

Proposition 1 For each $(\underline{h}, \sigma)$ there exists a unique renovation cost $I^{*}(\underline{h})>0$, such that $\partial J(\underline{h}, \sigma) / \partial g>0$ for all $I(\underline{h})<I^{*}(\underline{h})$ and $\partial J(\underline{h}, \sigma) / \partial g<0$ for all $I(\underline{h})>I^{*}(\underline{h})$.

\section{Proof See appendix E.}

Because the optimal scrapping horizon is the same for all unskilled workers, it is interesting to determine whether workers getting trained benefit from a lower renovation horizon than unskilled workers not getting trained. If this is the case, we might find a situation where it is optimal to update the technology employed by an unskilled worker getting trained and destroy the job occupied by an unskilled worker not getting trained, i.e. $R(\underline{h}, \sigma)<T(\underline{h})<R\left(\underline{h}^{n}, \sigma\right)$.

\subsubsection{Relationship between the training decision and the renovation horizon}

Does the presence of unskilled workers getting trained stimulate firms to renovate at a faster rate? We will provide an answer to this question in three steps. Firstly, we will determine the optimal renovation horizon associated with the last unskilled worker getting trained. Secondly, we will compare this optimal 
renovation horizon with that associated with unskilled workers not getting trained. Finally, we will compare the renovation horizons for workers below $\tilde{\sigma}$ and above $\tilde{\sigma}$.

Proposition 2: There is a unique pair $(R(\underline{h}, \tilde{\sigma}), \widetilde{\sigma})$ simultaneously satisfying training choices and the optimal renovation date.

Proof: See appendix F.

Does training accelerate or delay renovation? Let us compare the two FOCs to calculate the renovation horizons for the last unskilled worker getting trained $(R(\underline{h}, \tilde{\sigma}))$ and for unskilled workers not getting trained $\left(R\left(\underline{h}^{n}, \sigma\right)\right)$ :

$$
\begin{aligned}
b \underline{h} & =\frac{x \underline{h}}{e^{g R\left(\underline{h}^{n}, \sigma\right)}}-(r+\delta-g)(J(\underline{h}, \sigma)-I(\underline{h})) \text { for } \sigma>\tilde{\sigma} \\
b \underline{h} & =\frac{x \underline{h}}{e^{g R(\underline{h}, \widetilde{\sigma})}}-(r+\delta-g)(J(\bar{h}, \widetilde{\sigma})-I(\underline{h})) \text { for } \sigma=\tilde{\sigma}
\end{aligned}
$$

The last worker getting trained, the $\tilde{\sigma}$-worker, receives the same wage as unskilled workers not getting trained. However, since $J(\bar{h}, \widetilde{\sigma})>J(\underline{h}, \sigma>\tilde{\sigma})$, it is easy to confirm that $R(\underline{h}, \tilde{\sigma})<R\left(\underline{h}^{n}, \sigma\right)$.

What about the relationship between the renovation horizon of workers with $\sigma<\tilde{\sigma}$ and $\sigma>\tilde{\sigma}$ ?

Corollary: The renovation horizon is smaller for workers getting trained $(\sigma \leq \tilde{\sigma})$ than for workers not getting trained $\sigma>\tilde{\sigma}$.

Proof: See appendix G.

Since firms renovate jobs occupied by unskilled workers getting trained sooner than jobs occupied by unskilled workers not getting trained, the larger the proportion of workers getting trained in an economy, the higher the probability of a dominant capitalization effect at the aggregate level when growth accelerates.

\subsubsection{Relationship between growth and the decision to train, $(g, \tilde{\sigma})$}

How is the proportion of workers receiving training affected by technological progress?

Proposition 3: An acceleration in the growth rate increases the proportion of unskilled workers getting trained as long as $\pi$ is either sufficiently small $(\delta>\pi)$ or sufficiently large with respect to $\delta, r$ or $g$.

Proof: See appendix H.

This implies that, when the probability of human capital depreciation is either very low (so that an unskilled worker becoming skilled is very likely to retain her human capital level during an unemployment period) or very high (so that firms have an incentive to renovate positions occupied by unskilled workers 
receiving training since they pay low wages for skilled positions), the proportion of workers deciding to seek training increases with the growth rate ${ }^{16}$.

\section{Numerical simulations}

Theoretical analysis shows that there is an equilibrium where an acceleration in the growth rate certainly increases the employment of skilled workers, for whom the capitalization effect is always dominant due to the hypothesis that $I(\bar{h}) \rightarrow 0$ (skill-biased technological progress). Results are more ambiguous when analyzing unskilled workers. If $I(\underline{h})>J^{*}\left(\underline{h},\left.\sigma\right|_{\sigma<\tilde{\sigma}}\right)>J^{*}\left(\underline{h},\left.\sigma\right|_{\sigma>\tilde{\sigma}}\right)$ the creative destruction effect is always dominant when growth accelerates. If $J^{*}\left(\underline{h},\left.\sigma\right|_{\sigma<\tilde{\sigma}}\right)>I(\underline{h})>J^{*}\left(\underline{h},\left.\sigma\right|_{\sigma>\tilde{\sigma}}\right)$ the capitalization effect may dominate when growth accelerates for workers getting trained while the creative destruction effect is dominant for those not getting trained. If $J^{*}\left(\underline{h},\left.\sigma\right|_{\sigma<\tilde{\sigma}}\right)>J^{*}\left(\underline{h},\left.\sigma\right|_{\sigma>\tilde{\sigma}}\right)>I(\underline{h})$, it is in the interest of the firm to renovate any job occupied by an unskilled worker.

In this section, we will present numerical experiments to test the capacity of the model to reproduce the impact of growth on the unemployment rate suggested by Pissarides and Vallanti (2007): based on OECD data (1965-1995) they estimate that a one percentage point increase in the growth rate should reduce unemployment around 1 to 1.5 percentage points.

The numerical values of the parameters corresponding to the benchmark simulation are summarized in Table 1. We have assumed a matching function of the Cobb-Douglas form: $M=m_{0} u^{\alpha} v^{1-\alpha}$, where $\alpha$ is the elasticity with regard to unemployment and it is assumed to be equal to 0.5 (see Petrongolo and Pissarides (2001)). As suggested in Pissarides and Vallanti (2007), we consider that, although a job may be "destroyed" on average after ten years in the sense of Davis, Haltiwanger, and Schuh (1996) (for US) or OECD (1996) (for other western countries), the position is not necessarily closed down but brought back into use at a later date. In this case, the expected life of the job for discounting purposes will be the life of the position, not the job. This definition of "job destruction" is also employed by GomezSalvador, Messina, and Vallanti (2004) who consider a sample of continuing firms ${ }^{17}$ for 15 European countries for the period 1992-2000. They estimate annual "job destruction" rate in France (a typical

\footnotetext{
${ }^{16}$ To our knowledge, there is no empirical literature analyzing whether a growth acceleration fosters an increase in the proportion of employed workers getting trained. However, since the seventies the source of growth has been skill-biased technological progress favoring the relative demand for qualified workers and bringing about an increase in the relative unemployment rate for unskilled workers (see Berman, Bound, and Griliches (1994), Machin and Van Reenen (1998), Caroli and Van Reenen (2001) or Bresnahan, Brynjolfsson, and Hitt (2002)). Since there are increased employment opportunities for qualified workers, the share of unskilled workers for whom it will become reasonable to get trained (given the training cost) should increase.

${ }^{17}$ In Davis, Haltiwanger, and Schuh (1996) job destruction equals employed losses summed over all business units that contract or shut down, whereas in Gomez-Salvador, Messina, and Vallanti (2004) they do not include firms' closures.
} 
Table 1: Baseline Parameters Values

\begin{tabular}{|c|c|c|c|}
\hline Productivity parameters & $\mu=2$ & & $\iota=1$ \\
\hline Renovation parameters & $I_{U N}=4$ & & $I_{U F}=4$ \\
\hline Interest rate & $r$ & $=$ & .04 \\
\hline Matching elasticity & $\alpha$ & $=$ & .5 \\
\hline Matching efficiency & $m_{0}$ & $=$ & 0.1 \\
\hline Recruiting cost & $c$ & $=$ & .33 \\
\hline Exogenous separation rate & $\delta$ & $=$ & .032 \\
\hline Outside option & $b$ & $=$ & .57 \\
\hline Probability of human capital depreciation & $\pi$ & $=$ & 0.5 \\
\hline
\end{tabular}

European country in labor market terms) to be equal to $3.2 \%$, implying that the life expectancy of a position is at least 31 years. This average duration depends on both the exogenous and the endogenous separation rate. Concerning endogenous separation, in our model firms destroy a job in order to fill it again with a new worker and a more modern technology (the position is not destroyed) since this is less costly than keeping the same worker and updating the technology. Therefore, for discounting purposes considering the expected life of the position and not that of the job corresponds well with the rationale of our theoretical framework.

We will set the outside option based on the values estimated in OECD (2006) (Table 3.2, average net replacement rate over 60 months of unemployment), $b=0.57$. As noted in Pissarides (1990), indexing unemployment benefit to the average wage creates complications in a model like ours where the equilibrium is characterized by a conditional wage distribution and not by a unique wage rate. In this case a convenient shortcut is to define benefits in terms of average productivity, which is exogenous and around unity in our model.

To ensure that, among unskilled workers receiving training, those with the highest inherent ability are updated before the others, we assume that productivity in skilled positions is linked not only to the worker's human capital level, but also to her ability or talent for learning how to use new technologies, $x=\mu \cdot e^{-\iota \sigma}$. As shown in the following section, this hypothesis reduces the negative impact of growth on unemployment but we adopt it since it avoids counterintuitive renovation decisions among unskilled getting trained ${ }^{18}$.

\footnotetext{
${ }^{18}$ The set of simulations presented in this paper (with directed search, undirected search, wage posting and wage bargaining) have been implemented under the hypothesis $x(\bar{h})$. Main results hold. These simulations are available upon request.
} 
Human capital levels for unskilled and skilled workers are given by $\{\underline{h}, \bar{h}\} \epsilon\{0.6,1\}$. This gap between high and low skills is taken from Jung and Kuester (2011). Obviously there are no formal empirical estimates of these values. However, given that education in France begins at the age of four, if we consider unskilled workers as those who have completed compulsory education (ending at the age of 16) and skilled workers as those with a university education (ending at the age of 23), unskilled workers have around $60 \%$ of skilled workers' years of education.

We will assume a continuum of training costs (ability levels) defined between 0 and 1, i.e. $\sigma \epsilon[\underline{\sigma}, \bar{\sigma}]=$ $\sigma \epsilon[0,1]$. The matching efficiency parameter $\left(m_{0}=0.1\right)$, the productivity parameters $(\mu=2, \iota=1)$ and the renovation costs associated with each type of unskilled worker (i.e. $I_{U N}=I_{U F}=4$ ) are set to reproduce the unemployment rate observed for a typical European economy (an aggregate unemployment rate around $8 \%$ for a growth rate equal to $2 \%$ ) as well as the average unemployment duration (around two years).

With this calibration, the proportion of skilled workers or unskilled workers getting trained, represented by the value $\tilde{\sigma}$, increases by $5.2 \%$ when growth progresses from $1 \%$ to $2 \%$, reaching almost $90 \%$ of the total population ${ }^{19}$ at $g=2 \%$. But what is the impact on the aggregate unemployment rate?

The first row of table 2 reveals a key result: an increase of one percentage point in the growth rate (from $1 \%$ to $2 \%$ ) reduces the aggregate unemployment rate 1.1209 percentage points. This corresponds with the estimates of Pissarides and Vallanti (2007) and confirms that, at the aggregate level, the capitalization effect is dominant ${ }^{20}$. A detailed analysis by qualification level reveals that the relationship between unemployment and growth varies according not only to the skill level of the worker but also to the training decision. Indeed, while the correlation between unemployment and growth is negative when we consider skilled workers and unskilled workers getting trained, it becomes positive as soon as we focus on unskilled workers not getting trained. The lower reduction in skilled unemployment compared with unskilled unemployment is explained by the lower starting level of skilled workers' unemployment rate.

Figure 1 shows the renovation and scrapping horizon for each worker category. For unskilled workers not getting trained (first panel of figure 1) the renovation horizon (starred line) is above the scrapping

\footnotetext{
${ }^{19}$ In the introduction we presented Eurostat statistics on the proportion of workers receiving on-the-job training. This proportion reaches $78 \%$ in Denmark, $66 \%$ in the Netherlands, $57 \%$ in Germany and $62 \%$ in France. Using our calibration, we find that unskilled workers receiving training plus workers who are already skilled represent $90 \%$ of the population. Therefore our results include not only workers receiving training as shown in the Eurostat statistics, but also all skilled workers.

${ }^{20}$ If instead of taking our preferred definition of job destruction (i.e. continuing firms, the position is not closed down but brought back into use at a latter date) we had assumed the definition of Davis, Haltiwanger, and Schuh (1996), that is, $\delta=0.1$, the reduction in the aggregate unemployment rate would have been equal to 0.9699 which remains close to the semi-elasticity of unemployment with respect to growth estimated in Pissarides and Vallanti (2007) (we set $b=0.6, m_{0}=0.31, \mu=1.55$ and $\iota=0.5$ so as to obtain an aggregate unemployment rate around $8 \%$ for $g=2 \%)$.
} 
Table 2: The impact of growth on aggregate unemployment by qualification. Directed search hypothesis

\section{Benchmark simulation}

\begin{tabular}{c|ccccc}
\hline \hline & Usk+Uunskt & Uunskt & Usk & Uunsk & Utot \\
\hline$\Delta U$ if g $\uparrow$ from $1 \%$ to $2 \%$ & -1.3073 & -1.1339 & -0.1734 & 1.9047 & -1.1209 \\
\hline \hline
\end{tabular}

\section{Robustness tests}

\begin{tabular}{|c|c|c|c|c|c|}
\hline \multicolumn{6}{|c|}{ Productivity in skilled workers positions is not ability-dependent } \\
\hline & Usk+Uunskt & Uunskt & Usk & Uunsk & Utot \\
\hline$\Delta U$ if $\mathrm{g} \uparrow$ from $1 \%$ to $2 \%$ & -2.1513 & -2.0083 & -0.1430 & 3.1917 & -1.1774 \\
\hline \multicolumn{6}{|c|}{ Different human capital gaps } \\
\hline & Usk+Uunskt & Uunskt & Usk & Uunsk & Utot \\
\hline \multicolumn{6}{|l|}{$\Delta U$ if $\mathrm{g} \uparrow$ from $1 \%$ to $2 \%$} \\
\hline for $\bar{h}-\underline{h}=0.35$ & -1.1530 & -0.9774 & -0.1757 & 2.6161 & -0.6990 \\
\hline \multicolumn{6}{|l|}{$\Delta U$ if $\mathrm{g} \uparrow$ from $1 \%$ to $2 \%$} \\
\hline for $\bar{h}-\underline{h}=0.45$ & -1.4643 & -1.3014 & -0.1629 & 1.1059 & -1.5143 \\
\hline \multicolumn{6}{|c|}{ Different human depreciation probabilities } \\
\hline & Usk+Uunskt & Uunskt & Usk & Uunsk & Utot \\
\hline \multicolumn{6}{|l|}{$\Delta U$ if $\mathrm{g} \uparrow$ from $1 \%$ to $2 \%$} \\
\hline for $\pi=0.9$ & -1.3562 & -1.2774 & -0.0788 & 1.7772 & -1.1412 \\
\hline \multicolumn{6}{|l|}{$\Delta U$ if $\mathrm{g} \uparrow$ from $1 \%$ to $2 \%$} \\
\hline for $\pi=0.1$ & -1.1524 & -0.6511 & -0.5012 & 2.5376 & -1.3454 \\
\hline
\end{tabular}

Usk=Skilled unemployed; Uunskt=Unskilled unemployed getting trained; Uunsk=Unskilled unemployed not getting trained; Utot $=$ Total unemploy 

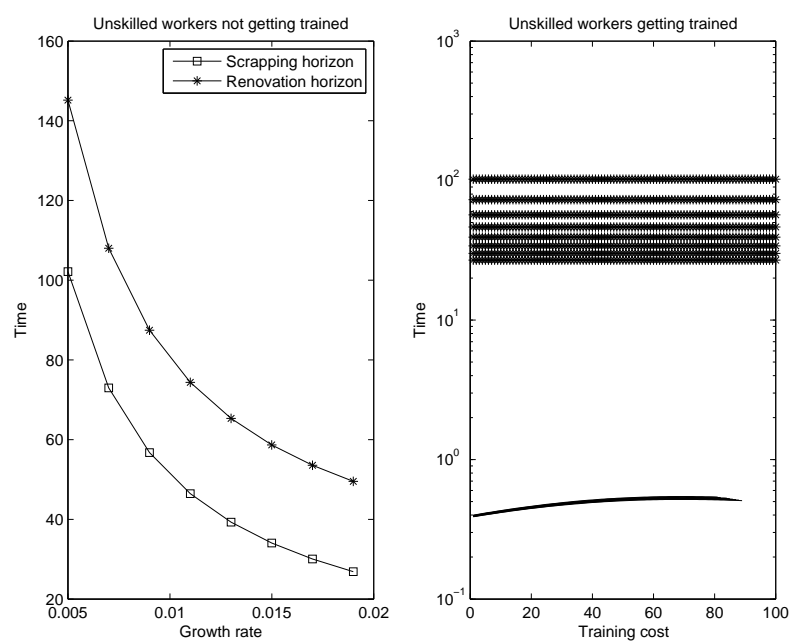

The $\mathrm{X}$-axis represents the growth rate progression from 0 to $2 \%$ in panel $(i)$ and the support of ability levels in panel (ii). The $\mathrm{Y}$-axis of panel $(i)$ shows the temporal horizon associated with positions occupied by unskilled workers not getting trained. The squared curve in this panel represents the scrapping horizon while the starred line shows the renovation horizon. The Y-axis of panel (ii) represents the temporal horizon associated with unskilled workers getting trained. The starred lines show the scrapping horizon, which is identical for all ability levels and decreases with the growth rate (the lower lines show the scrapping horizons associated with higher growth rates than the upper lines). The dark lines represent the renovation horizon, which increases with the training cost (the reason why these lines are positively sloped) and decreases with the growth rate (lower lines are associated with higher growth rates than upper lines). Note that the scale on the Y-axis is logarithmic, not linear.

Figure 1: Unskilled workers getting trained: scrapping horizon and renovation horizon.

horizon (squared line), meaning that it is never in the interest of the firm to renovate this type of job (endogenous destruction occurs before renovation). Thus there is a dominant creative destruction effect ${ }^{21}$. When considering unskilled workers getting trained (right hand panel of figure 1), the renovation horizon (dark lines) is below the scrapping horizon (starred lines) for each growth level, meaning that it is in the interest of the firm to update technology when growth accelerates. In spite of the logarithmic scale used for the Y-axis, the reduced renovation horizon values make it difficult to visualize two of the main theoretical results found in this paper. First, there is a negative relationship between the renovation horizon and the growth rate (for example, for $\sigma=0$ the optimal renovation horizon progresses from 1.045 when $g=0.05 \%$ to 0.9279 when the growth rate reaches $2 \%$ ). Second, as already stated, the share of trained workers increases by $5.2 \%$ (the dark positive sloping lines become longer as $g$ increases).

\footnotetext{
${ }^{21}$ Note that, when the growth rate equals $2 \%$ the optimal destruction horizon for the firm is around 27 years, which may seem a little high but is actually lower than the 45 years estimated by Pissarides and Vallanti (2007). Furthermore, Gomez-Salvador, Messina, and Vallanti (2004) estimate that, in a typical European economy (France), the annual job destruction rates in the manufacturing sector are equal to $3.2 \%$, implying that the life expectancy of an establishment is at least 31 years (average duration of a job which depends on the exogenous separation rate but also on endogenous job destruction). Therefore, an optimal scrapping horizon of 27 years when $\mathrm{g}=2 \%$ is a realistic result.
} 


\subsection{Robustness tests}

In order to test the robustness of our numerical results we will propose, on the one hand, a new definition of the productivity function for a skilled position, and on the other hand, we will modify the relative levels of human capital and the values of the human capital depreciation parameter.

Let us first assume that the productivity of skilled workers no longer increases as the worker's talent increases. Specifically, we consider that skilled workers' productivity is homogeneous among those workers and is equal to $\bar{h}$. The impact of this change is potentially ambiguous. On the one hand, in our benchmark specification, highly skilled workers could possess a productivity level above their own human capital since $x(\bar{h}, \sigma)=\mu e^{-\iota \sigma} \bar{h}>\bar{h}$ for low values of $\sigma$ (high talented workers). On the other hand, low talented workers will benefit now from a higher productivity level with respect to the benchmark simulation, since $x(\bar{h}, \sigma)=\mu e^{-\iota \sigma} \bar{h}<\bar{h}$ for high values of $\sigma$.

The second row of table 2 reveals that the productivity gain effect is greater than the productivity loss effect. When growth accelerates, the expected profit of renovating the technology used in a position occupied by an unskilled worker getting trained increases. Firms then update at a faster rate. As a result, the aggregate unemployment rate decreases by 1.1774 percentage points when growth accelerates by one percentage point. This reduction is above the one in the benchmark simulation.

The second sensitivity test we will propose involves modifying the size of the gap between skilled workers' human capital and unskilled workers' human capital. We will modify this gap in both directions: up and down. Specifically, we will first reduce the gap from $0.4(\bar{h}-\underline{h}=1-0.6=0.4)$ to 0.35 and then increase it to 0.45 points. The larger the human capital gap the larger the expected gain for unskilled workers getting trained when they become skilled and the larger the expected profit for firms updating the technology used by an unskilled worker getting trained. This produces an increase in the proportion of workers getting trained as well as an increase in the rate of technological updating. Therefore, the larger (lower) the human capital gap between skilled and unskilled workers, the larger (lower) the impact of a growth acceleration in the unemployment rate. The third and the fourth rows of table 2 confirm these results.

Finally, the choice of the parameter value $\pi$ remains unmotivated. It would therefore be interesting to carry out a sensitivity analysis on this parameter. The results are shown in the fifth and sixth rows of table 2. As observed they are not noticeably modified by the value of $\pi$. Even when adopting extreme values, such as $\pi=0.1$ or $\pi=0.9$, we find that an increase of one percentage point in the growth rate increases the share of unskilled workers getting trained (Proposition 3 is satisfied) and decreases the unemployment rate around $[1.14,1.34]$ percentage points, which corresponds well to the estimations by Pissarides and Vallanti (2007). For $\pi=0.9$, skilled workers ask for a lower wage. Because skilled workers earn a lower wage, the expected profit from skilled positions increases, and this leads firms to update positions occupied by unskilled workers getting trained sooner. The unemployment rate associated with this category of workers falls. However, the reduction in the skilled workers' unemployment rate is so 
small $^{22}$ that, at the aggregate level, we observe a similar reduction of the unemployment rate as in the benchmark. The opposite applies when $\pi=0.1$, since the decrease in the skilled's unemployment rate more than doubles the benchmark which allows to overcome the weaker reduction in the unemployment rate of unskilled getting trained.

\section{Conclusion}

By ignoring the skill-biased nature of recent technological progress, previous literature on the relationship between growth and unemployment underestimates the potential productivity gains associated with technological progress and thus underestimates the impact of growth on unemployment. The main contribution of this paper consists in introducing human capital issues into an endogenous job destruction model in the style of Mortensen and Pissarides (1998) so as to fully capture productivity improvements linked to recent technological progress. Our framework allows for heterogeneous skills, on-the-job training, capital-skill complementarity and human capital depreciation. We find that human capital magnifies the impact of growth on the unemployment rate through three channels: firstly, using heterogeneous skills, our framework is able to highlight the skill-biased nature of recent technological progress by considering that jobs occupied by skilled workers will benefit from a capitalization effect; secondly, for reasonable parameter values, the share of workers getting trained increases when growth accelerates. Since firms are more likely to update positions occupied by workers getting trained, the probability of a dominant capitalization effect in these jobs increases. Finally, because of the complementary relation between skills and technological progress, when a position occupied by an unskilled worker getting trained is updated, the worker becomes skilled since the acquired human capital becomes employable. The capitalization effect is always dominant in the skilled segment.

Evidently, the model presents some limitations. An interesting extension of the model will be to combine skill heterogenous and age heterogeneous workers. In principle, it should be more interesting for firms to update jobs occupied by young workers rather than by old workers since, for a given updating cost, the working horizon of a senior is shorter. However, human capital can counterbalance this result. Thanks to seniority an older worker may be endowed with a valuable general human capital that makes him more productive in case of technological or organizational updating. This can yield firms to update positions occupied by senior workers in spite of their shorter horizon. Another possible extension would be to consider unobserved heterogeneity of skilled and unskilled workers as unique determinant of the worker's productivity and thus as a unique determinant of the firm's updating decision. In this context, we could consider that only the worker knows his type. The firm should post contracts proposing different timing of technological renovation and wages. These contracts should induce workers to reveal their type

\footnotetext{
${ }^{22}$ Because unemployed skilled workers depreciate with probability 0.9 , their unemployment level is very low, which explains the tiny decrease in the unemployment rate.
} 
(revelation mechanism). We leave this point for future research.

\section{References}

Acemoglu, D., and J-S. Pischke. 1998. "Why do firms train? Theory and Evidence." Quarterly Journal of Economics 113 (February): 79-119.

Aghion, P., and P. Howitt. 1994. "Growth and Unemployment." Review of Economic Studies 61 (3): $477-496$.

Autor, D., L. Katz, and M. Kearney. 2008. "Trends in the U.S. Wage Inequality: Re-Assessing the Revisionists." Review of Economic and Statistics 90 (May): 300-323.

Autor, D., F. Levy, and M. Kearney. 2006. "The Polarization of the US Labor Market." American Economic Review 96 (2): 189-194 (January).

Autor, D., F. Levy, and R. Murnane. 2003. "The Skill Content of Recent Technological Change: An Empirical Exploration." Quarterly Journal of Economics 118 (4): 1279-1333 (November).

Becker, G. 1964. Human Capital. The University Chicago Press.

Berman, E., J. Bound, and Z. Griliches. 1994. "Changes in the demand for skilled labor within U.S. manufacturing: evidence from the Annual Survey of Manufacturers." Quarterly Journal of Economics 109:367-397.

Black, S., and L. Lynch. 2001. "How to compete: the impact of workplace practices and information technology on productivity." Review of Economics and Statistics 83:434-445.

Blanchard, O., and J. Wolfers. 2000. "The Role of Shocks and Institutions in the Rise of European Unemployment: The Aggregate Evidence." The Economic Journal 110 (462): 1-33 (March).

Bresnahan, T.F., E. Brynjolfsson, and L.M. Hitt. 2002. "Information Technology, Workplace organization, and the Demand for skilled Labor: Firm-Level Evidence." The Quarterly Journal of Economics 117 (1): 339-376.

Caroli, E., and J. Van Reenen. 2001. "Skilled Biased Technological Change? Evidence from a Pannel of British and French Establishments." Quarterly Journal of Economics 116 (4): 1449-1492.

Carre, M., and D. Drouot. 2004. "Pace versus type: the effect of economic growth on unemployment and wage patterns." Review of Economic Dynamics 7:737-757. 
Chari, V.V, and H. Hopenhayn. 1991. "Vintage human capital, growth and the diffusion of new technology." Journal of Political Economy 99 (6): 1142-1165.

Davis, S.J., J.C. Haltiwanger, and S. Schuh. 1996. Job Creation and Destruction. MIT Press.

Gomez-Salvador, R., J. Messina, and G. Vallanti. 2004. "Gross job flows and institutions in Europe." Labour Economics 11 (4): 469-485 (August).

Goos, M., and A. Maning. 2007. "Lousy and Lovely Jobs: the Rising Polarization of Work in Britain." Review of Economics and Statistics 89 (1): 118-133 (February).

Hall, R., and P. Milgrom. 2008. "The Limited Influence of Unemployment on the Wage Bargain." American Economic Review 98 (4): 1653-1674 (September).

Jovanovic, B., and Y. Nyarko. 1996. "Learning by doing and the choice of technology." Econometrica 64 (6): 1299-1310.

Juhn, C., K. Murphy, and B. Pierce. 1993. "Wage inequality and Returns to Skill." The Journal of Political Economy 101 (3): 410-442.

Jung, P., and K. Kuester. 2011. "The (Un)importance of Unemployment Fluctuations for Welfare." Journal of Economic Dynamics and Control 35 (10): 1744-1768.

Krusell, P., L.E. Ohanian, J.V. Rios-Rull, and G.L. Violante. 2000. "Capital skill complementarity and inequality: A macroeconomic analysis." Econometrica 68 (5): 1029-53.

Laing, D., T. Palivos, and P. Wang. 1995. "Learning, matching and growth." Review of Economic Studies 62:115-129.

Langot, F., and E. Moreno-Galbis. 2008. "Does the growth process discriminate against older workers?" GAINS Working Paper.

Lemieux, T. 2006. "Increasing Residual Wage Inequality: Composition Effects, Noisy Data or Rising Demand for Skill?" American Economic Review 96 (3): 461-498.

Lindbeck, A., and D. Snower. 2000. "Multitask Learning and the Reorganization of Work: From Tayloristic to Holistic Organization." Journal of Labor Economics 18 (3): 353-376 (July).

Ljunqvist, J., and T. Sargent. 2008. "Two questions about European Unemployment." Econometrica $76: 1-29$.

Machin, S., and J. Van Reenen. 1998. "Technology and changes in skill structure: Evidence from seven OECD countries." Quarterly Journal of Economics 113:1215-44.

Maurin, E., and D. Thesmar. 2004. "Changes in the Functional Structure and Demand for Skills." Journal of Labor Economics 22 (3): 639-664.

Michaud, J.B. 2007. "Creative destruction with on the job effect." CEP Discussion Paper, no. 835.

Mortensen, D., and C. Pissarides. 1998. "Technological Progress, Job Creation and Job Destruction." Review of Economic Dynamics 1:733-753. 
OECD. 1996. Job Creation and loss: analysis, policy and data development. OECD.

2006. "OECD Employment Outlook 2006." Technical Report, OECD.

Parente, S. 1994. "Technology adoption, learning by doing and economic growth." Journal of Economic Theory 63 (2): 346-369 (August).

Petrongolo, B., and C. Pissarides. 2001. "Looking Back into the Black Box: a Survey of the Matching Function." Journal of Economic Literature 39:390-431.

Pissarides, C. 1990. Equilibrium Unemployment Theory. Edited by MIT Press. Cambridge, Massachusetts: MIT Press.

. 2009. "The Unemployment Volatility Puzzle: Is Wage Stickiness the Answer?" Econometrica 77 (5): 1339-1369.

Pissarides, C., and G. Vallanti. 2007. "The impact of TFP growth on steady-state unemployment." International Economic Review 48 (May): 607-640.

Shimer, R. 2005. "On-the-Job Search and Strategic Bargaining." European Economic Review 50 (4): 811-830.

Spitz-Oener, A. 2006. "Technical Change, Job Tasks and Rising Educational Demands: Looking Outside the Wage Structure." Journal of Labor Economics 24 (2): 235-270.

Tripier, F. 2007. "The long run relationship between growth and unemployment. A transatlantic perspective." Mimeo.

\section{A The optimal scrapping time}

When renovation cost is relatively high, it is not in the interest of the firm to update technology since it is more profitable to offer a new vacancy directly. In this case, unskilled workers have no incentive to seek training since their position will not be renovated. Thus there is one scrapping time associated with skilled positions and one scrapping time associated with unskilled positions. The asset values of filled vacancies are respectively given by:

$$
\begin{aligned}
J(\tau, t, \bar{h}, \sigma) & =\max _{T^{\bar{h}}} \int_{t}^{\tau+T^{(\bar{h}, \sigma)}} e^{-(r+\delta)(s-t)}\left[p(\tau) x(\sigma) \bar{h}-w^{s}(\tau, t, \bar{h}) \bar{h}\right] d s \\
J(\tau, t, \underline{h}, \sigma) & =\max _{T_{\underline{h}}} \int_{t}^{\tau+T^{\underline{h}}} e^{-(r+\delta)(s-t)}[p(\tau) x \underline{h}-w(\tau, s, \underline{h}) \underline{h}] d s .
\end{aligned}
$$

Maximizing $J(\tau, t, \bar{h}, \sigma)$ with respect to $T^{(\bar{h}, \sigma)}$ yields the following FOC:

$$
b \bar{h}-\pi \frac{b \bar{h}-b \underline{h}}{r+\pi-g}=\frac{x(\sigma) \bar{h}}{e^{g T^{(\bar{h}, \sigma)}}}
$$

Once $T^{(\bar{h}, \sigma)}$ is determined from $(27)$, we can replace it in the firm's asset value function leading to $J^{*}(\bar{h}, \sigma)=\int_{0}^{T^{(\bar{h}, \sigma)}} e^{-(r+\delta) s}\left[x(\sigma) \bar{h}\left(1-e^{g\left(s-T^{(\bar{h}, \sigma)}\right)}\right)\right] d s$. 
The optimal scrapping time associated with a machine used by an unskilled worker is given by:

$$
b \underline{h}=\frac{x \underline{h}}{e^{g T \underline{h}}},
$$

Replacing in $J(\underline{h}, \sigma)$ yields: $J^{*}(\underline{h}, \sigma)=\int_{0}^{T^{\underline{h}}} e^{-(r+\delta) s}\left[x \underline{h}\left(1-e^{g\left(s-T^{\underline{h}}\right)}\right)\right]$.

\section{B Proof Lemma 1}

Given a stationary time path for future labor market tightness, the value of a new job is proportional to productivity on the technology frontier, i.e. $J(t, t, \bar{h}, \sigma)=p(t) J(\bar{h}, \sigma)$. Replacing in $J(t, t, \bar{h}, \sigma)$ when $\tau=t=0$ leads to:

$$
\begin{aligned}
J(\bar{h}, \sigma)= & \max _{R(\bar{h}, \sigma)} \int_{0}^{R(\bar{h}, \sigma)} e^{-(r+\delta) s}\left[x(\sigma) \bar{h}-e^{g s} w(\bar{h}, \sigma)\right] d s \\
& +e^{-(r+\delta-g)(R(\bar{h}, \sigma))}[J(\bar{h}, \sigma)-I(\bar{h})]
\end{aligned}
$$

The optimal renovation time is determined by maximizing (29), which leads to the FOC:

$$
w(\bar{h}, \sigma)=\frac{x(\sigma) \bar{h}}{e^{g R(\bar{h}, \sigma)}}-(r+\delta-g)(J(\bar{h}, \sigma)-I(\bar{h}))
$$

Replacing $w(\bar{h}, \sigma)$ in $(29)$ by the previous equation yields our "job renovation rule":

$$
I(\bar{h})=x(\sigma) \bar{h} \int_{0}^{R(\bar{h}, \sigma)} e^{-(r+\delta) s}\left(1-e^{g(s-R(\bar{h}, \sigma))}\right) d s
$$

\section{Proof Lemma 2}

The FOC associated with the optimal renovation date is

$$
w(\underline{h}, \sigma)=\frac{x \underline{h}}{e^{g R(\underline{h}, \sigma)}}-(r+\delta-g)(J(\bar{h}, \sigma)-I(\underline{h}))
$$

Replacing (32) in (14) yields:

$$
I(\underline{h})=J(\bar{h}, \sigma<\tilde{\sigma})-J(\underline{h}, \sigma<\tilde{\sigma})+x \underline{h} \int_{0}^{R(\underline{h}, \sigma)} e^{-(r+\delta) s}\left(1-e^{g(s-R(\underline{h}, \sigma))}\right)
$$

\section{Proof Lemma 3}

The FOC of (16) is given by:

$$
w(\underline{h})=\frac{x \underline{h}}{e^{g R\left(\underline{h}^{n}, \sigma\right)}}-(r+\delta-g)(J(\underline{h}, \sigma)-I(\underline{h}))
$$


Replacing in (16) yields:

$$
I(\underline{h})=x \underline{h} \int_{0}^{R\left(\underline{h}^{n}, \sigma\right)} e^{-(r+\delta) s}\left(1-e^{g\left(s-R\left(\underline{h}^{n}, \sigma\right)\right)}\right)
$$

\section{E Proof Proposition 1}

- Unskilled workers not getting trained:

$$
\begin{aligned}
\lim _{(I(\underline{h}), R(\underline{h}, \sigma)) \rightarrow(0,0)} J(\underline{h}, \sigma) & =\lim _{(I(\underline{h}), R(\underline{h}, \sigma)) \rightarrow(0,0)}\left[I(\underline{h})+\frac{x \underline{h}-e^{g R(\underline{h}, \sigma)} w(\underline{h}, \sigma)}{\left.(r+\delta-g) e^{g R(\underline{h}, \sigma)}\right]}\right. \\
& =\frac{x \underline{h}-w(\underline{h}, \sigma)}{r+\delta-g}
\end{aligned}
$$

which is increasing in $g\left(\frac{\partial J(\underline{h}, \sigma)}{\partial g}>0\right)$.

It is therefore sufficient to prove that $\frac{\partial^{2} J(\underline{h}, \sigma)}{\partial g \partial I(\underline{h})}<0$ to obtain a critical $I^{*}(\underline{h})$ from which the creative-destruction effect dominates the capitalization effect:

$$
\frac{\partial J(\underline{h}, \sigma)}{\partial I(\underline{h})}=\frac{-1}{e^{(r+\delta-g) R(\underline{h}, \sigma)}-1}<0 \quad \text { if } \quad(r+\delta-g)>0
$$

deriving by $g$ leads to

$$
\frac{\partial^{2} J(\underline{h}, \sigma)}{\partial I \partial g}=\frac{e^{(r+\delta-g) R(\bar{h}, \sigma)}\left(-R(\underline{h}, \sigma)+(r+\delta-g) \frac{\partial R(\underline{h}, \sigma)}{\partial g}\right)}{\left(e^{(r+\delta-g) R(\underline{h}, \sigma)}-1\right)^{2}}<0
$$

since

$$
\frac{\partial R(\underline{h}, \sigma)}{\partial g}=\frac{\int_{0}^{R(\underline{h}, \sigma)} e^{-(r+\delta) s} e^{g(s-R(\underline{h}, \sigma))}(s-R(\underline{h}, \sigma)) d s}{g \int_{0}^{R(\underline{h}, \sigma)} e^{-(r+\delta) s} e^{g(s-R(\underline{h}, \sigma))} d s}<0
$$

Because $\frac{\partial J(\underline{h}, \sigma)}{\partial g}>0$ when $I(\underline{h}) \rightarrow 0$ and $\frac{\partial^{2} J(\underline{h}, \sigma)}{\partial I \partial g}<0$ for all $I(\underline{h})$, there is a unique $I^{*}(\underline{h})$ from which the capitalization effect is dominated by the creative destruction effect.

- For unskilled workers getting trained we will use a similar procedure. Replacing equation (32) in (14) and integrating leads to:

$$
\begin{aligned}
J(\underline{h}, \sigma) & =\frac{x \underline{h}}{r+\delta}\left(1-e^{-(r+\delta) R(\underline{h}, \sigma)}\right)-\frac{w(\underline{h}, \sigma)}{r+\delta-g}\left(1-e^{-(r+\delta-g) R(\underline{h}, \sigma)}\right)+ \\
& +e^{-(r+\delta-g) R(\underline{h}, \sigma)}(J(\bar{h}, \sigma)-I(\underline{h})) \\
J(\underline{h}, \sigma) & =x \underline{h}\left[\frac{1-e^{-(r+\delta) R(\underline{h}, \sigma)}}{r+\delta}-\frac{1-e^{-(r+\delta-g) R(\underline{h}, \sigma)}}{(r+\delta-g) e^{g R(\underline{h}, \sigma)}}\right]+J(\bar{h}, \sigma)-I(\underline{h})
\end{aligned}
$$


Calculating the limit of the previous expression when $(I(\underline{h}), R(\underline{h}, \sigma)) \rightarrow(0,0)$ yields:

$$
\lim _{(I(\underline{h}), R(\underline{h}, \sigma)) \rightarrow(0,0)} J(\underline{h}, \sigma)=J(\bar{h}, \sigma)+x \underline{h} \cdot 0=J(\bar{h}, \sigma)=\frac{x \bar{h}-w(\bar{h}, \sigma)}{r+\delta-g}
$$

which is increasing in $g\left(\frac{\partial J(\underline{h}, \sigma)}{\partial g}>0\right.$ for $\left.\sigma<\tilde{\sigma}\right)$. Again, it is sufficient to prove that $\frac{\partial^{2} J(h, \sigma)}{\partial g \partial I(\underline{h})}<0$ for $\sigma<\tilde{\sigma}$, to obtain a critical $I^{*}(\underline{h})$ from which the creative-destruction effect dominates the capitalization effect:

$$
\frac{\partial J(\underline{h}, \sigma)}{\partial I(\underline{h})}=-e^{-(r+\delta-g) R(\underline{h}, \sigma)}<0
$$

then,

$$
\frac{\partial^{2} J(\underline{h}, \sigma)}{\partial I(\underline{h}) \partial g}=-e^{-(r+\delta-g) R(\underline{h}, \sigma)} R(\underline{h}, \sigma)-e^{-(r+\delta-g) R(\underline{h}, \sigma)}(-(r+\delta-g)) \frac{\partial R(\underline{h}, \sigma)}{\partial g}<0
$$

since $\frac{\partial R(\underline{h}, \sigma)}{\partial g}<0$.

\section{F Proof Proposition 2}

The link between the renovation horizon and the training cost for critical ability level $\tilde{\sigma}$ is found using equations (11) and (32) in appendix C:

$$
\begin{aligned}
b \underline{h} & =\frac{x \underline{h}}{e^{g R(\underline{h}, \tilde{\sigma})}}-(r+\delta-g)(J(\bar{h}, \tilde{\sigma})-I(\underline{h})) \\
\tilde{\sigma} & =(r+\delta-g)\left(\frac{e^{-(r+\delta-g) R(\underline{h}, \tilde{\sigma})}}{1-e^{-(r+\delta-g) R(\underline{h}, \tilde{\sigma})}}\right) \frac{b(\bar{h}-\underline{h})}{r+\pi-g}
\end{aligned}
$$

In the first equation, the left hand-side shows the $\widetilde{\sigma}$-worker's wage, whereas the right hand-side shows the optimal renovation date. The higher the value of $\tilde{\sigma}$ the lower the productivity if the worker becomes skilled (since $x^{\prime}(\sigma)<0$ ) and hence the lower the value of the filled vacancy, $J(\bar{h}, \widetilde{\sigma})$. This favors a later renovation horizon. In other words, the right hand side demonstrates a positive relationship between $\tilde{\sigma}$ and $R(\underline{h}, \tilde{\sigma})$.

A detailed analysis of the second equation reveals a negative relationship between $R(\underline{h}, \tilde{\sigma})$ and $\widetilde{\sigma}$ (since $\left.\frac{\partial}{\partial R(\underline{h}, \tilde{\sigma})}\left(\frac{e^{-(r+\delta-g) R(\underline{h}, \tilde{\sigma})}}{1-e^{-(r+\delta-g) R(\underline{h}, \tilde{)})}}\right)<0\right)$.

Thus we deduce that there is a unique intersection point $(R(\underline{h}, \tilde{\sigma}), \widetilde{\sigma})$ simultaneously satisfying these two equations.

\section{G Proof Corollary}

Let us start by simply replacing equation (32) in expression (14), which yields:

$$
I(\underline{h})=J(\bar{h}, \sigma<\tilde{\sigma})-J(\underline{h}, \sigma<\tilde{\sigma})+x \underline{h} \int_{0}^{R(\underline{h}, \sigma)} e^{-(r+\delta) s}\left(1-e^{g(s-R(\underline{h}, \sigma))}\right)
$$


We will proceed with two steps. Firstly, it is easy to show that the inequality $J(\bar{h}, \sigma<\tilde{\sigma})>J(\underline{h}, \sigma>\tilde{\sigma})$ holds true. The minimum instantaneous profit obtained in a job occupied by an unskilled $\tilde{\sigma}$-worker equals $\underline{h}(x-b)$, which is below the profit associated with a skilled position, $\bar{h}(x(\tilde{\sigma})-b)+\pi \frac{b(\bar{h}-\underline{h})}{r+\pi-g}$, as long as productivity differentials offset unemployment benefit differentials, which will be the case if $\bar{h} x(\tilde{\sigma}) \geq \underline{h} x$ (the adopted calibration ensures that this inequality is always satisfied). In the same way, the profit associated with the $\sigma=0$-worker (the worker with the highest ability) equals $\underline{h}(x-b)+(r+$ $\delta-g)\left(\frac{e^{-(r+\delta-g) R(\underline{h}, \sigma)}}{1-e^{-(r+\delta-g) R(\underline{h}, \sigma)}}\right) \frac{b(\bar{h}-\underline{h})}{r+\pi-g}$. When comparing it with the profit associated with a skilled position, $\bar{h}(x(\tilde{\sigma})-b)+\pi \frac{b(\bar{h}-\underline{h})}{r+\pi-g}$, we realize that, since $\underline{h}(x-b)<\bar{h}(x(\tilde{\sigma})-b)$, to ensure that the profit associated with a skilled worker is greater than that of the most profitable low-skilled worker, it is sufficient (not necessary) to have $\pi>(r+\delta-g) \frac{e^{-(r+\delta-g) R(\underline{h}, \sigma)}}{1-e^{-(r+\delta-g) R(\underline{h}, \sigma)}}$. This inequality is likely to be satisfied since, for reasonable parameter values, the renovation horizon for $\sigma=0$ is very small. Therefore this ensures that $J(\bar{h}, \sigma<\tilde{\sigma})>J(\underline{h}, \sigma<\tilde{\sigma}), \forall \sigma \epsilon[0, \tilde{\sigma}]$.

Secondly, the integral term $\int_{0}^{R(\underline{h}, \sigma)} e^{-(r+\delta) s}\left(1-e^{g(s-R(\underline{h}, \sigma))}\right) d s$ corresponds to equation (17) but with a different renovation horizon. As far as $J(\bar{h}, \sigma<\tilde{\sigma})>J(\underline{h}, \sigma>\tilde{\sigma})$ this integral term must necessarily have an upper limit below that of equation (17), i.e. $\int_{0}^{R\left(\underline{h}^{n}, \sigma\right)} e^{-(r+\delta) s}\left(1-e^{g\left(s-R\left(\underline{h}^{n}, \sigma\right)\right)}\right) d s$, that is $R(\underline{h}, \sigma)$ must necessarily be below $R\left(\underline{h}^{n}, \sigma\right)$.

\section{H Proof Proposition 3}

We will proceed step by step. Firstly, since $b \underline{h}=\frac{x \underline{h}}{e^{g R(\underline{\sigma}, \tilde{\sigma})}}-(r+\delta-g)(J(\bar{h}, \widetilde{\sigma})-I(\underline{h}))$ is $\left.)\right)$ is positively sloped

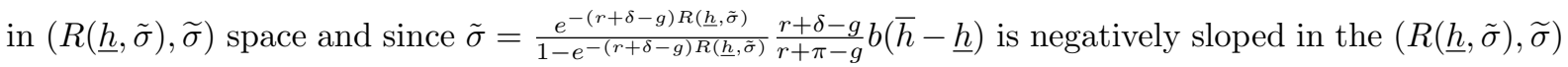
space, there is a unique intersection point between both lines which determines the equilibrium $\tilde{\sigma}$.

Secondly, we will use a static comparative analysis to determine the impact of a growth acceleration in each of these locus. Let's start with $b \underline{h}=\frac{x \underline{h}}{e^{g R(\underline{h}, \tilde{\sigma})}}-(r+\delta-g)(J(\bar{h}, \widetilde{\sigma})-I(\underline{h}))$. For a given $\tilde{\sigma}$ and since $J(\bar{h}, \tilde{\sigma})=\frac{x(\tilde{\sigma}) \bar{h}-b \bar{h}}{r+\delta-g}$ we find:

$$
g \frac{\partial R(\underline{h}, \tilde{\sigma})}{\partial g}=-R(\underline{h}, \tilde{\sigma})-I e^{g R(\underline{h}, \tilde{\sigma})}<0
$$

so that the locus shifts left.

Regarding $\tilde{\sigma}=\frac{e^{-(r+\delta-g) R(\underline{h}, \tilde{\sigma})}}{1-e^{-(r+\delta-g) R(\underline{h}, \tilde{\sigma})}} \frac{r+\delta-g}{r+\pi-g} b(\bar{h}-\underline{h})$, for a given $R(\underline{h}, \tilde{\sigma})$, when growth accelerates we find:

$$
\frac{\partial \tilde{\sigma}}{\partial g}=\frac{b(\bar{h}-\underline{h}) e^{-(r+\delta-g) R(\underline{h}, \tilde{\sigma})}}{(r+\pi-g)\left(1-e^{-(r+\delta-g) R(\underline{h}, \tilde{\sigma})}\right)}\left(\frac{r+\delta-g}{1-e^{-(r+\delta-g) R(\underline{h}, \tilde{\sigma})}}+\frac{\delta-\pi}{r+\pi-g}\right)
$$

The derivative in equation (42) is unambiguously positive if $\delta>\pi$ (sufficient condition). For $\delta<\pi$, the derivative remains positive for sufficiently low values of $\frac{\delta-\pi}{r+\pi-g}$ which actually requires $\pi$ to be relatively

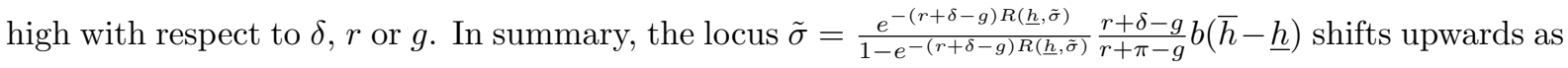
long as $\pi$ is either sufficiently small (smaller than $\delta$ ) or sufficiently large (ensuring a low value of $\frac{\delta-\pi}{r+\pi-g}$ ). 


\section{Undirected search}

In undirected search hypothesis, firms do not aim a vacancy at a particular skill segment $(v(h)=v)$, which implies that insofar as the surplus associated with a match is positive, the match takes place independently of the worker's human capital level. Jobs and workers meet pairwise according to the matching function $M(u, v)$ having the same properties as previously. Labor market tightness is defined as $\theta=\frac{v}{u}$. The probability of filling a vacancy is given by $q(\theta)=M(u, v) / v=M(1 / \theta, 1)$. Similarly, the probability of finding a job is given by $p(\theta)=M(u, v) / u=M(1, \theta)$. The probability of filling a vacancy with a skilled worker will be given by $q(\theta) \frac{u(\bar{h}, \sigma)}{u}$, with an unskilled worker getting trained by $q(\theta) \frac{u(\underline{\underline{h}, \sigma<\tilde{\sigma}})}{u}$ and an unskilled worker not getting trained by $q(\theta) \frac{u(\underline{h}, \sigma>\tilde{\sigma})}{u}$. Optimal renovation horizons as well as the value of a filled job are not modified by the search hypothesis. The job creation rule as well as the unemployment rates are now given by:

- Job creation rule:

$$
\begin{aligned}
\frac{c}{q(\theta)}= & \int_{\underline{\sigma}}^{\tilde{\sigma}} \frac{u(\underline{h}, \sigma)}{u} J(\underline{h}, \sigma<\tilde{\sigma}) d G(\sigma) \\
& +\int_{\tilde{\sigma}}^{\bar{\sigma}} \frac{u(\underline{h}, \sigma)}{u} J(\underline{h}, \sigma>\tilde{\sigma}) d G(\sigma)+\int_{\underline{\sigma}}^{\tilde{\sigma}} \frac{u(\bar{h}, \sigma)}{u} J(\bar{h}, \sigma<\tilde{\sigma}) d G(\sigma) \equiv \bar{J}
\end{aligned}
$$

- Unemployment rates of skilled and unskilled not receiving training when renovation is optimal:

$$
u(\underline{h}) / P(\underline{h})=u^{R}(\underline{h})=\frac{\delta}{p(\theta)\left(1-e^{-\delta R(\underline{h}, \sigma)}\right)+\delta} \quad u(\bar{h}) / P(\bar{h})=u^{R}(\bar{h})=\frac{\delta}{p(\theta)+\pi+\delta}
$$

- Unemployment rates of unskilled not receiving training when renovation is optimal:

$$
u(\underline{h})=\frac{\delta}{\delta+p(\theta)}
$$

- Unemployment rates of unskilled when renovation is not optimal:

$$
\frac{u(\underline{h})}{P(\underline{h})}=\frac{\delta}{\delta+p(\theta)\left(1-e^{-\delta T^{\underline{h}}}\right)}
$$

Using the same parameter values as in table 1, we replicate the same simulation exercises as under the directed search hypothesis. Results remain robust (see table 3).

\section{J Wage bargaining}

The rigid wage representation assumed in this paper, where wages are disconnected from labor market tightness, is particularly relevant to European economies (and indeed to many western economies). The simplest way to obtain this wage representation is to assume that firms own all the bargaining power and pay workers their reservation wage (which is independent from workers' productivity and market tightness). This simplified framework enables us to analyze the relationship between renovation, training and growth proposed in section 5.1. Evidently, this hypothesis is quite restrictive. We propose then 
Table 3: The impact of growth on aggregate unemployment by qualification. Undirected search hypothesis

\section{Benchmark simulation}

\begin{tabular}{c|ccccc}
\hline \hline & Usk+Uunskt & Uunskt & Usk & Uunsk & Utot \\
\hline$\Delta U$ if g $\uparrow$ from $1 \%$ to $2 \%$ & -1.3135 & -1.0989 & -0.2147 & 1.4906 & -1.0646 \\
\hline \hline
\end{tabular}

Robustness tests

\begin{tabular}{l|ccccc}
\hline \hline \multicolumn{5}{c}{ Productivity in skilled workers positions is not ability-dependent } \\
\hline & Usk+Uunskt & Uunskt & Usk & Uunsk & Utot \\
\hline$\Delta U$ if $\mathrm{g} \uparrow$ from $1 \%$ to $2 \%$ & -2.1658 & -2.0680 & -0.0977 & 2.3106 & -1.2830 \\
\hline \hline \multicolumn{5}{c}{ Different human capital gaps } \\
\hline & Usk+Uunskt & Uunskt & Usk & Uunsk & Utot \\
\hline $\begin{array}{l}\Delta U \text { if } \mathrm{g} \uparrow \text { from } 1 \% \text { to } 2 \% \\
\text { for } \bar{h}-\underline{h}=0.35\end{array}$ & -1.1782 & -1.0018 & -0.1764 & 1.8329 & -0.7282 \\
$\Delta U$ if $\mathrm{g} \uparrow$ from $1 \%$ to $2 \%$ \\
for $\bar{h}-\underline{h}=0.45$
\end{tabular}

Usk=Skilled unemployed; Uunskt=Unskilled unemployed getting trained; Uunsk=Unskilled unemployed not getting trained; Utot=Total unemploy 
in this appendix a new version of the model (we consider again the directed and the undirected search case) where wages are still rigid but workers have a positive bargaining power. The wage setting process I propose was introduced by Hall and Milgrom (2008). The concept behind it is as follows: once the worker meets an employer, threatening to walk away and permanently terminate the bargain, is not credible. The bargainers have a joint surplus, arising from search frictions, that glues them together. The main threat in this framework is to extend bargaining (disagreement payoff) rather than to terminate it (outside-option payoff). The result is to loosen the tight connection between wages and outside conditions.

We will assume that the worker receives a payoff $p(t) b h$ for $h=\bar{h}, \underline{h}$ in case negotiation breaks down but also when the agreement is delayed. For the firm, we will assume that there is no cost as long as bargaining continues. Firms and workers renegotiate the division of the match product $p(\tau) x(h, \sigma)$, so that the outcome of the symmetric alternating-offers game for skilled and unskilled workers is :

$$
\begin{aligned}
w(\tau, t, \bar{h}, \sigma) & =\gamma p(\tau) x(\bar{h}, \sigma)+(1-\gamma) p(t) b \bar{h} \quad \text { and } \\
w(\tau, t, \underline{h}) & =\gamma p(\tau) x(\underline{h})+(1-\gamma) p(t) b \underline{h}
\end{aligned}
$$

where $\gamma$ and $(1-\gamma)$ represent the bargaining power of each party. The central result of this bargaining process is that the real wage does not depend on labor market tightness. Thus the real wage is rigid. As per the usual wage setting-rule, the real wage increases with the generosity of unemployment benefits and the worker's productivity.

\section{J.1 The agents' behavior}

- The functional form of the present discounted value of earnings associated with the employment and unemployment situation is not modified by the assumption of wage bargaining.

- The functional form associated with the value of an empty vacancy is not modified by the wage bargaining assumption whereas the job renovation rules become:

$$
\begin{aligned}
& I(\bar{h})=(1-\eta) x(\sigma) \bar{h} \int_{0}^{R(\bar{h}, \sigma)} e^{-(r+\delta) s}\left(1-e^{g(s-R(\bar{h}, \sigma))}\right) d s \\
& I(\underline{h})=J(\bar{h}, \sigma<\tilde{\sigma})-J(\underline{h}, \sigma<\tilde{\sigma})+(1-\eta) x \underline{h} \int_{0}^{R(\underline{h}, \sigma)} e^{-(r+\delta) s}\left(1-e^{g(s-R(\underline{h}, \sigma))}\right) \\
& I(\underline{h})=(1-\eta) x \underline{h} \int_{0}^{R\left(\underline{h}^{n}, \sigma\right)} e^{-(r+\delta) s}\left(1-e^{g\left(s-R\left(\underline{h}^{n}, \sigma\right)\right)}\right)
\end{aligned}
$$

- The optimal scrapping times are still determined by equations (27) and (28).

- The training decision: modifying the wage determination process complicates determination of the critical training cost above which it is no longer in the interest of unskilled workers to seek training. The threshold value of $\sigma$ will now depend on labor market tightness. However, labor market tightness also depends on $\tilde{\sigma}$ since firms post vacancies using the average value of a filled vacancy as a reference. To determine the average value we need to know the proportion of each 
type of worker in the total population (see equations (20) and (43)). Whether we use directed or undirected search hypothesis, we need to solve the system of equations simultaneously.

The undirected search hypothesis

$$
\begin{gathered}
\tilde{\sigma} \int_{0}^{R(\underline{h}, \sigma)} e^{-(r+\delta-g) s} d s=e^{-(r+\delta-g) R(\underline{h}, \sigma)}[W(\bar{h}, \sigma)-W(\underline{h}, \sigma)] \\
\tilde{\sigma}\left(\frac{1-e^{-(r+\delta-g) R(\underline{h}, \sigma)}}{r+\delta-g}\right)=e^{-(r+\delta-g) R(\underline{h}, \sigma)}[W(\bar{h}, \sigma)-W(\underline{h}, \sigma)]
\end{gathered}
$$

Using equations (1) and (2) allows us to determine $[W(\bar{h}, \sigma)-W(\underline{h}, \sigma)]$.

Using $r U(t, \bar{h}, \sigma)=p(t) b \bar{h}+\theta q(\theta)[W(t, t, \bar{h}, \sigma)-U(t, \bar{h}, \sigma)]-\pi[U(t, \bar{h}, \sigma)-U(t, \underline{h}, \sigma)]+\dot{U}(t, \bar{h}, \sigma)$ and $r U(t, \underline{h}, \sigma)=p(t) b \underline{h}+\theta q(\theta)[W(t, t, \underline{h}, \sigma)-U(t, \underline{h}, \sigma)]+\dot{U}(t, \underline{h}, \sigma)$ allows us to determine $[U(\bar{h}, \sigma)-$ $U(\underline{h}, \sigma)]$ :

$$
\begin{aligned}
W(\bar{h}, \sigma)-W(\underline{h}, \sigma) & =\left(1-e^{(r+\delta-g) R(\underline{h}, \sigma)}\right) \frac{w(\bar{h}, \sigma)-w(\underline{h})+\sigma+\delta(U(\bar{h}, \sigma)-U(\underline{h}, \sigma))}{r+\delta-g}(54) \\
U(\bar{h}, \sigma)-U(\underline{h}, \sigma) & =\frac{b(\bar{h}-\underline{h})+p(\theta)(W(\bar{h}, \sigma)-W(\underline{h}, \sigma))}{r+\pi+p(\theta)-g}
\end{aligned}
$$

Substituting $[W(\bar{h}, \sigma)-W(\underline{h}, \sigma)]$ and $[U(\bar{h}, \sigma)-U(\underline{h}, \sigma)]$ in (53) yields the following expression for the threshold value of $\sigma$ :

$$
\tilde{\sigma}=\left(w(\bar{h}, \sigma)-w(\underline{h})+\frac{\delta b(\bar{h}-\underline{h})}{r+\pi+p(\theta)-g}\right) \frac{e^{-(r+\delta-g) R(\underline{h}, \sigma)}}{1-e^{-(r+\delta-g) R(\underline{h}, \sigma)}} \frac{(r+\delta-g)(r+\pi+p(\theta)-g)}{(r+\pi-g)(r+\delta-g)+p(\theta)(r-g)}
$$

\section{The directed search hypothesis}

Using equations (1), (2) and (4), (5) allows us to determine the expressions for $[W(\bar{h}, \sigma)-W(\underline{h}, \sigma)]$, $[U(\bar{h}, \sigma)-U(\underline{h}, \sigma)],[W(\bar{h}, \sigma)-U(\bar{h}, \sigma)]$ and $[W(\underline{h}, \sigma)-U(\underline{h}, \sigma)]$ :

$$
\begin{aligned}
W(\bar{h}, \sigma)-W(\underline{h}, \sigma) & =\left(1-e^{(r+\delta-g) R(\underline{h}, \sigma)}\right) \frac{w(\bar{h}, \sigma)-w(\underline{h})+\sigma+\delta(U(\bar{h}, \sigma)-U(\underline{h}, \sigma))}{r+\delta-g} \\
U(\bar{h}, \sigma)-U(\underline{h}, \sigma) & \left.=\frac{b(\bar{h}-\underline{h})+p(\theta(\bar{h}))(W(\bar{h}, \sigma)-U(\bar{h}, \sigma))-p(\theta(\underline{h}))(W(\underline{h}, \sigma)-U(\underline{h}, \sigma)}{r+\pi-g}\right) \\
W(\bar{h}, \sigma)-U(\bar{h}, \sigma) & =\frac{1}{r+\delta+p(\theta(\bar{h}))-g}(w(\bar{h}, \sigma)-b \bar{h}+\pi(U(\bar{h}, \sigma)-U(\underline{h}, \sigma))) \\
W(\underline{h}, \sigma)-U(\underline{h}, \sigma) & =\frac{1}{r+\delta+p(\theta(\underline{h}))-g}(w(\underline{h}, \sigma)-b \underline{h}-\sigma \\
& \left.+\frac{(r+\delta-g) e^{(r+\delta-g) R(\underline{h}, \sigma)}}{1-e^{(r+\delta-g) R(\underline{h}, \sigma)}}(W(\bar{h}, \sigma)-W(\underline{h}, \sigma))\right)
\end{aligned}
$$

Replacing (57), (58), (59) and (60) in (53), allows to rewrite $\tilde{\sigma}$ as a function of the labor tightness for each market segment (skilled and unskilled). 
Table 4: Modified Parameters Values

\begin{tabular}{l|rr|rc}
\hline & \multicolumn{2}{|c}{ Directed search } & \multicolumn{2}{c}{ Undirected search } \\
\hline \hline Productivity parameter & $\mu=1.85$ & $\iota=.5$ & $\mu=2$ & $\iota=.7$ \\
Matching efficiency & $m_{0}=0.17$ & $m_{0}=0.16$ \\
Outside option & $b=.55$ & $b=.55$ \\
\hline \hline
\end{tabular}

\section{J.2 Numerical simulations}

The numerical values of the parameters are barely modified with respect to the benchmark simulation of Table 1 . We have marginally adjusted the values of the outside option (the value of $b$ is reduced from 0.57 to 0.55$)$, the productivity parameters $(\mu$ and $\iota)$ and the matching efficiency parameter $\left(m_{0}\right)$. All other parameter values, as well as the functional forms of the matching function and the productivity of skilled workers, remain unchanged. Aggregate unemployment rate remains around $8 \%$ and average unemployment duration around two years.

Table 5: The impact of growth on aggregate unemployment by qualification in the presence of wage bargaining

Directed search hypothesis

\begin{tabular}{l|ccccc}
\hline \hline & Usk +Uunskt & Uunskt & Usk & Uunsk & Utot \\
\hline$\Delta U$ if $\mathrm{g} \uparrow$ from $1 \%$ to $2 \%$ & -1.2800 & -1.1286 & -0.1513 & 1.8505 & -1.2914 \\
\hline \hline \multicolumn{7}{c}{ Undirected search hypothesis } \\
\hline & Usk+Uunskt & Uunskt & Usk & Uunsk & Utot \\
\hline$\Delta U$ if $\mathrm{g} \uparrow$ from $1 \%$ to $2 \%$ & -1.7249 & -1.4380 & -0.2869 & 0.8446 & -1.3469 \\
\hline \hline
\end{tabular}

Usk=Skilled unemployed; Uunskt=Unskilled unemployed getting trained; Uunsk=Unskilled unemployed not getting trained; Utot $=$ Total unemploy 